\title{
Effects of edge-stiffened web openings on the behaviour of cold- formed steel channel sections under compression
}

Boshan Chen ${ }^{\mathrm{a}}$, Krishanu Roy ${ }^{\mathrm{a}}$, Asraf Uzzaman ${ }^{\mathrm{b}}$, Gary M. Raftery ${ }^{\mathrm{a}}$, David Nash ${ }^{\mathrm{b}}$, G. Charles Clifton ${ }^{\mathrm{a}}$, Pouya Pouladia , James B.P. Lim ${ }^{\mathrm{a}}$

a Department of Civil and Environmental Engineering, The University of Auckland, New Zealand b Department of Mechanical and Aerospace Engineering, The University of Strathclyde, 75 Montrose Street, Glasgow G1 1XJ, United Kingdom

Abstract: The use of cold-formed steel (CFS) channel sections are becoming popular as the load-carrying members in building structures, and such channel sections often include web openings for the ease of installation of services. Traditional web openings are normally punched, and are unstiffened which can restrict the size and spacing of web openings. Recently, a new generation of CFS channel sections with edge-stiffened web openings has been developed, and is widely used in New Zealand. However, no experimental investigation has been reported in the literature for such channel sections under compression. In this paper, a total of 75 results comprising 26 axial compression tests and 49 finite element analysis results are reported on the compression resistance of CFS channel sections with both edge-stiffened and unstiffened web openings. For comparison, channel sections without web openings were also tested. For all specimens, initial imperfections were measured using a laser scanner. A nonlinear elasto-plastic finite element model was also developed, and the results showed good agreement with the test results. A parametric study was conducted using the validated finite element model to investigate the effect of opening spacing and column length on compression resistance of channel sections. It is shown that for the case of a channel section having seven edge-stiffened web openings, the compression resistance increased by as much as $22 \%$, 
1 compared to a plain channel section. For comparison, the same section having unstiffened web

2 openings had a $20 \%$ reduction in compression resistance, compared to a plain channel section.

3 Keywords: Cold-formed steel, Channel sections, Axial compression tests, Edge-stiffened web

4 openings, Finite element analysis 


\section{Notation}

$a \quad$ Diameter of circular web openings;

$A_{\mathrm{g}} \quad$ Gross cross-sectional area;

$b_{f} \quad$ Overall flange width of section;

$b_{l} \quad$ Overall lip width of section;

$b_{f} / t \quad$ Ratio of flange to thickness;

$b_{l} / t \quad$ Ratio of lip to thickness;

CFS Cold-formed steel;

$\mathrm{COV} \quad$ Coefficient of variation;

$d \quad$ Overall web depth of section;

DSM Direct strength method;

E Young's modulus of elasticity;

FEA Finite element analysis;

$f_{o l} \quad$ Elastic local buckling stress;

$f_{\text {od }} \quad$ Elastic distortional buckling stress;

$h \quad$ Depth of the flat portion of web;

$L \quad$ Total length of the CFS column;

LVDT Linear variable displacement transducers;

$L / t \quad$ Ratio of length to thickness;

$n \quad$ Opening number;

$P_{c r d} \quad$ Elastic distortional buckling load;

$P_{c r e} \quad$ Elastic flexural buckling load;

$P_{c r l} \quad$ Elastic local buckling load;

$P_{\mathrm{D} 1} \quad$ Un-factored design axial strength;

$P_{\text {DSM }} \quad$ Axial strength from the direct strength method;

$P_{\text {EXP }} \quad$ Axial strength from experiments; 


\begin{tabular}{|ll|}
\hline$P_{\mathrm{FEA}}$ & Axial strength from the finite element analysis; \\
$P_{\mathrm{ne}}$ & Nominal overall buckling strength; \\
$P_{\mathrm{nl}}$ & Nominal local buckling strength; \\
$P_{\mathrm{nd}}$ & Nominal distortional buckling strength; \\
$q$ & Length of edge-stiffener; \\
$r$ & Radius of gyration of full unreduced cross-section axis of buckling; \\
$r_{\mathrm{i}}$ & Inside corner radius of section; \\
$s$ & Opening spacing; \\
$t$ & Thickness of section; \\
$\sigma_{0.2}$ & Static $0.2 \%$ proof stress; \\
$\sigma_{u}$ & Static ultimate tensile strength; \\
&
\end{tabular}




\section{$1 \quad 1$ Introduction}

The use of cold-formed steel (CFS) channel sections as the primary load-carrying members in buildings is increasing recently. CFS channel sections often include circular web openings that have been pre-punched for ease of installation of services. Such openings are usually unstiffened (Fig. 1(a)). In the literature, extensive work has been reported on the reduction in compression resistance of channel sections having such unstiffened web openings by Kulatunga, Macdonald et al. [1-2] and Moen and Schafer [3-4] covering compression, Uzzaman et al. [5-8] and Lian et al. [9-12] covering web crippling, Pham [13], Pham et al. [14] and Keerthan et al. [15-16] covering shear. Also, for compression, Singh et al. [17] conducted an experimental study to investigate the effect of web openings on the compression resistance, albeit for CFS tubular sections. In a recent study, Yu et al. [18] conducted an analytical study to investigate the effects of multiple unstiffened web openings on the distortional buckling behaviour and Zhao et al. [19] proposed modified direct strength method formulas for CFS with unstiffened web openings.

Recently, a new generation of CFS channel sections with edge-stiffened circular web openings (Fig. 1(b)), developed by Howick Ltd.[20], are widely used in New Zealand. As can be seen from Fig. 1(b), there is a continuous edge stiffener around the perimeter of the circular web openings. In the literature, limited work has been reported on the edge-stiffened web openings. A numerical study was reported by Yu et al. [21] covering bending, and it was found that edge-stiffened web openings can improve the compression resistance of CFS channel sections by an average of $14 \%$, compared to that of a plain channel section. Grey and Moen [22] presented procedures for approximating the elastic critical buckling load (or moment) of CFS columns and beams due to the presence of edge-stiffened web openings, without the need for an eigen-value finite element analysis. In terms of experimental tests, Uzzaman et al. [23] 
1 presented results for the case of web crippling. Similarly, to the finding of Yu et al. [21], it was

2 found that channel sections having an edge-stiffened circular web opening had an improved

3 web crippling strength, almost as much as that of a plain channel section without web opening.

No experimental work in the literature, however, has been reported for CFS channel sections with edge-stiffened web openings subject to axial compression. Furthermore, current

6 design guidance i.e. the American Iron and Steel Institute (AISI) [24] and the Australian and 7 New Zealand Standards (AS/NZS) [25] does not include direct guidance for CFS channel sections with edge-stiffened web openings in compression. The limitations of existing design code procedures for CFS members with edge-stiffened web openings can affect the design flexibility and decreases the reliability of cold-formed products in the modern construction 11 industry.

This paper presents an experimental and numerical investigation on the compression resistance of CFS channel sections with edge-stiffened circular web openings. In total, the results of 26 tests are reported, which include 10 tests on specimens with edge-stiffened web openings, 10 tests on specimens with unstiffened web openings and the remaining 6 tests on specimens without web openings.

The effect of the column length and opening spacing were considered in the experimental investigation. The material properties were determined from tensile coupon tests and the initial imperfections were measured using a laser scanner. The results of load-axial displacement, load-lateral displacement, load-strain relationship and failure modes were reported.

A non-linear elasto-plastic finite element model was developed which included initial imperfections. The finite element model was validated against the test results. The validated model was used for the purposes of a parametric study on the effects of the column length and opening spacing on the compression resistance. 


\section{$1 \quad 2$ Experimental Study}

$2 \quad 2.1$ Test specimens

In this study, a total of 26 CFS channel sections were tested to failure under axial

4 compression. Nominal cross-sections of test specimens considered in this paper is shown in

5 Fig. 3. Table 1 summarises the measured dimensions of test specimen. As can be seen from

6 Table 1, three different lengths $(L)$ were considered: $750 \mathrm{~mm}, 1300 \mathrm{~mm}$ and $1500 \mathrm{~mm}$. Three

7 different opening spacing (s) were considered as shown in Fig. 2 (390mm, 290mm and

8 190mm). The test specimens comprised of two different section sizes: C190 $\times 45 \times 15$ and

9 C240×45×15 channel sections (Fig. 3). The edge-stiffener length $(q)$ was fixed as $13 \mathrm{~mm}$.

$10 \quad 2.2$ Section labels

11 The specimens were labelled such that the nominal dimensions of the cross sections, the

12 nominal length of specimens, the type of web opening and the openings number were expressed

13 as a label as shown in Fig. 4. For example, the label "C240×45×15-L1500-EH3-1" can be

14 interpreted as follows:

- The symbol $d \times b_{\mathrm{f}} \times b_{1}$ refers to the nominal dimensions of the cross sections in millimetres i.e. $240 \times 45 \times 15$ means $d=240 \mathrm{~mm} ; b_{\mathrm{f}}=45 \mathrm{~mm}$; and $b_{1}=15 \mathrm{~mm}$.

- "L1500" is the nominal length of the specimen in millimetres i.e. $1500 \mathrm{~mm}$.

- 'EH' identifies a web having an edge-stiffened web opening, 'UH' identifies a web having an unstiffened web opening, "NH' identifies a plain channel section having no

20 web opening.

21 - " 3 " represents the openings number.

- The last number " 1 " indicates the specimen number for a repeated group. 


\subsection{Material testing}

Tensile coupon tests were conducted to determine the material properties of the specimens and the coupons were obtained from the centre of the web plate in the longitudinal directions of the untested specimens in accordance with the British Standard for Testing and Materials [26].

The coupons were tested using Instron tensile testing machine (Fig. 5). A calibrated extensometer of $50 \mathrm{~mm}$ gauge length was used to determine the tensile strain of the coupons. The full stress-strain curves of coupons taken from the $C 190 \times 45 \times 15$ and $C 240 \times 45 \times 15$ channel sections are shown in Fig. 6. As can be seen from Table 2, the average yield strengths were $285 \mathrm{MPa}$ and $309 \mathrm{MPa}$ for the $\mathrm{C} 190 \times 45 \times 15$ and $\mathrm{C} 240 \times 45 \times 15$ channel sections, respectively.

\subsection{Test-rig and loading procedure}

A photograph of the test setup is shown in Fig. 7 (a). Also, a schematic drawing of the test setup is shown in Fig. 7 (b). A total of three LVDTs (Linear variable differential transformers) were used to record the specimen displacements. The axial shortening of the specimens was recorded from the readings of LVDT-1 and the lateral displacements were recorded from the readings of LVDT-2 and LVDT-3 at mid-height of the channel sections. Fig. 8 shows the photograph of the pin support used in the test setup.

In order to ensure there was no gap between the two pin-ends and end plates of the specimen, all columns were loaded initially up to $25 \%$ of their expected failure load and then released. The axial load and the readings of the transducers were recorded by a data acquisition system at regular intervals during the tests. For CFS channel sections with web openings, four strain gauges (SG1, SG2, SG3 and SG4) were used to measure the strain values near the web openings and four different strain gauges (SG5, SG6, SG7 and SG8) were used to measure the strain values at mid-height of the CFS channel sections. 
Fig. 9 shows the locations of the strain gauges. A universal testing machine of $500 \mathrm{kN}$

2 capacity was used to apply the axial load to the CFS channel sections. The load was applied

3 through the centre of gravity (CG) of the specimens under pin-ended boundary conditions.

4 Displacement control was used in the column tests with a constant loading rate of $0.02 \mathrm{~mm} / \mathrm{s}$.

\section{$5 \quad 2.5$ Initial imperfections measurement}

Imperfections in CFS channel sections can occur as a result of transportation and

7 fabrication processes. Geometric imperfections significantly affect the stability of CFS members under compression. Therefore, the magnitude and shape of the imperfections of each specimen were recorded before undertaking the compression tests.

As can be seen from Fig. 10, a laser scanner assembly was used to measure the initial imperfections of all test specimens. The laser scanner assembly comprises a $5500 \times 2500 \times 1500$ $\mathrm{mm}$ steel frame which supports a travelling platform mounted on precision rails in the longitudinal direction. The platform supports a stepper motor, which allows displacementcontrolled motion using a rack and pinion system. The platform is designed to have a precision shaft in the transverse $(2500 \mathrm{~mm})$ direction which guides a moveable laser scanner.

The laser scanner was used to measure imperfections along six longitudinal lines on CFS channel sections with web openings and five longitudinal lines on CFS channel sections without web openings, as shown in Fig. 11. The laser scanner records readings at every 0.1 $19 \mathrm{~mm}$.

For CFS channel sections with web openings, the local imperfection was calculated by 21 subtracting the average reading along lines $\mathrm{W}-1$ and $\mathrm{W}-4$ from the readings taken along the line W-2 and W-3 (Fig. 12 (a)). The overall imperfections were calculated as the average value

23 of the readings recorded along the lines W-1 and W-4 at mid-height of the columns (Fig. 12 
1 (b)). The distortional imperfection was calculated as the maximum reading along the lines F-1

2 and F-2 (Fig. 12 (c)).

For CFS channel sections without web openings, the local imperfections were calculated

4 by subtracting the average readings recorded along the lines W-1 and W-3 from the readings

5 taken along the line W-2. A similar procedure was used to measure the initial imperfections of

6 CFS columns by Roy at al. [27] and Ye at al. [28-29].

7 A typical imperfection profile of C190 $\times 45 \times 15-\mathrm{L} 1500-\mathrm{EH} 3$ is plotted against the length

8 of the column in Fig. 12. Table 3 shows the maximum local, distortional and overall

9 imperfections of all test specimens.

$10 \quad 2.6$ Experimental results

11 Table 1 summarises the failure loads for all 26 test specimens. Those specimens with

$121300 \mathrm{~mm}$ and $1500 \mathrm{~mm}$ length failed through flexural buckling. As can be seen from Table 1,

$13 \mathrm{C} 240 \times 4 \times 15-\mathrm{L} 1500$ was tested with three repeats. The failure loads for all three tests were close

14 and the corresponding coefficient of variation (COV) was 0.02. Fig. 13 showed the deformed

15 shapes of the 1500 mm-length $C 240 \times 45 \times 15$ channel sections with unstiffened and edge-

16 stiffened web openings.

17 Fig. 14 showed the load versus axial shortening curves for specimens with various lengths, indicating that the column length can affect the compression resistance. Fig. 15 showed that the edge-stiffened web openings had a significant influence on compression resistance in this study. It was shown that for the case of a section having one edge-stiffened web opening,

21 the compression resistance increased by as much as $9.7 \%$, compared to that of the plain channel 22 sections. It can be seen from Fig. 16 and Table 1 that as more stiffened web openings were introduced; the failure load increased relative that to the plain section. However, for the 
1 unstiffened web openings, when more openings were introduced, the failure load reduced

2 relative to that of the plain section. For the case of the $C 240 \times 45 \times 15$ sections with 7 edge-

3 stiffened web openings, the failure load increased by $20 \%$. For the case of the $C 240 \times 45 \times 15$

4 sections with 5 edge-stiffened web openings, the failure load increased by $11.6 \%$.

Fig. 17 showed the axial load versus the lateral displacement at mid-height of specimens.

6 The readings of both LVDT-2 and LVDT-3 were consistent, indicating that the cross-sections

7 were not subject to twisting.

Fig. 18 showed the strain gauge readings near central circular web openings at mid-height

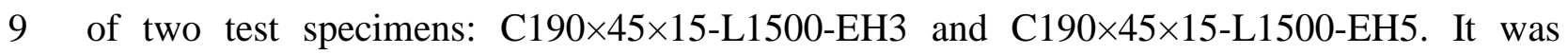

10 observed from the graphs that the test columns behaved in a linear way at low compressive

11 load, but gradually changed to non-linear behaviour as the compressive load increased.

\section{Numerical Study}

\subsection{General}

ABAQUS [30] was used to develop a nonlinear elasto-plastic finite element model to simulate the CFS channel sections with and without web openings subject to axial compression. In the finite element model, the measured cross-section dimensions and the material properties obtained from the coupon tensile tests were used. Modelling techniques are discussed in detail below.

\subsection{Modelling of geometry and material properties}

An elastic-plastic model was used for modelling the overall geometry of the channel sections with web openings (edge-stiffened and unstiffened) and without web openings. In order to define the isotropic yielding and plastic hardening of the steel, the von Mises yield surface was used in the classical metal plasticity model. The material properties were taken

24 from the tensile coupon tests and included in the FE models. As per the ABAQUS manual [30], 
1 the engineering material curve was converted into a true material curve by following the

2 equations below:

3

4

5 Where $E$ is the Young's modulus, $\sigma_{\text {true }}$ is the true stress, $\sigma_{\text {u }}$ is the ultimate tensile strength, $\sigma$

6 and $\varepsilon$ are the engineering stress and strain respectively in ABAQUS [30].

\section{$7 \quad 3.3$ FE meshing}

S4R shell elements were used to model the CFS channel sections. S4R elements allow each node to have three degrees freedom both along the translational and rotational directions. S4R elements are suitable for analysis of nonlinear problems as it accounts for finite membrane strains and arbitrarily large rotations. Rigid quadrilateral shell elements (R3D4) were used to model the upper and lower endplates. A mesh sensitivity analysis was performed to investigate the effect of different mesh sizes on the compression resistance of such columns. Based on the results of the mesh sensitivity analysis and considering computational time, appropriate mesh sizes were chosen for both channel sections and end plates. Across the length and width, a mesh size of $8 \mathrm{~mm} \times 8 \mathrm{~mm}$ was used for the convergence of both channel sections with and without web openings. Also, for the top and bottom base plates, a mesh size of $12 \mathrm{~mm} \times 12$ $\mathrm{mm}$ was used. Mesh refinement was made around the web openings for accurate finite element analysis. A typical finite element mesh is shown in Fig. 19 for C240×45×15-L1500-EH1.

\subsection{Boundary conditions and loading procedure}

Pin-pin boundaries were applied in all FE models for both the channel sections with and without web openings. Two rigid plates were used at the top and bottom ends of the CFS channel sections to simulate the test results. Pin-pin boundary conditions were modelled by 
1 applying rotations and displacements to both end plates through a reference point. The

2 reference point was considered as the center of gravity of the cross-section. The applied

3 boundary conditions in the FE model are shown in Fig. 19 for C240×45×15-L1500-EH1. To

4 simulate the experimental boundary conditions, the translation in the $x$ and $y$ are restrained,

5 while the vertical translation in the $\mathrm{z}$ direction was not restrained at the top reference point

6 (loading point). For bottom reference point (reaction point), the translation in the $x, y$ and $z$ are

7 restrained. It should be noted that two ends were free to rotate in minor axes. The displacement

8 control was used to apply the axial load through the reference point of the top base plate (Fig.

9 19).

$10 \quad 3.5$ Contact modelling

11 "Surface to surface" contact was used for modelling the interaction between the cross 12 sections of the CFS channel sections and top surface of end plates. The edges of the channel 13 section were modelled as the slave surface, while the top surfaces of the end plates were 14 considered as the master surface. The normal behaviour of the surface was defined as "hard", 15 indicating that no penetration of the surfaces into each other was allowed.

\section{$16 \quad 3.6$ Modelling of initial imperfections}

17 The buckling behaviour of channel sections with web openings (edge-stiffened and unstiffened) is dependent on many factors, such as the ratio of length to thickness $(L / t)$, flangethickness ratio $\left(b_{f} / t\right)$ and lip-thickness ratio $\left(b_{l} / t\right)$. Initial imperfections were considered in the FE model. Superimposition of local and overall imperfections was considered for accurate FE analysis. For all channel sections, eigenvalue analyses were performed. For local buckling, very small channel thickness was considered. However, for overall buckling, large channel thickness was used. For local and overall buckling modes, the lowest eigenmode was used in

24 ABAQUS [30]. Similar modelling techniques were presented in the literature for CFS single 
1 channel section and built-up columns by past researchers [31-36] to model local and overall

2 imperfections. From the results of the laser scanning, it was observed that the magnitude of

3 local imperfections were higher than expected values [28-29] as a result of minor deformations

4 introduced during transportation of the specimens. Therefore, these imperfection

5 measurements were used for validation of the FEA model. However, for the parametric study,

6 a local imperfection of $0.5 \%$ of the channel thickness was used in the parametric study. This

7 value was based on data from previous studies [31-36]. The magnitude of overall imperfections

8 used in the FE modelling of CFS channel sections were calibrated to the values measured from

9 the tests (section 2.5). The distortional imperfections were assessed in a number of the FE

10 models and it was found that they have negligible effect in terms of failure load and deformed

11 shape of the columns. The contours of local and overall buckling models are shown in Fig. 20

12 (a) and Fig. 20 (b), respectively.

$13 \quad 3.7$ Analysis procedure

14 Two different methods of analysis were used to model the CFS channel sections with

15 web openings (edge-stiffened and unstiffened) and without web openings: elastic buckling and

16 implicit dynamic analysis. Elastic buckling analyses were used to obtain the eigenvectors for

17 modelling the initial imperfections. Dynamic analysis with implicit time integration was used

18 for calculating the quasi-static response of the models.

193.8 Validation of the finite element model

20 In Table 4 , a comparison of the test results $\left(P_{\mathrm{EXP}}\right)$ with the numerical results $\left(P_{\mathrm{FEA}}\right)$ is 21 shown for $\mathrm{C} 190 \times 45 \times 15$ and $\mathrm{C} 240 \times 45 \times 15$ channel sections. The mean value of the $P_{\mathrm{EXP}} / P_{\mathrm{FEA}}$ 22 ratio is 0.99 with the corresponding coefficient of variation (COV) of 0.02 . Fig. 21 shows the 23 deformed shapes at failure from experiments and FEA. As can be seen, the deflected 24 shapes predicted by the FE model are similar to the deformed shapes as observed from the 
1 experiments. Load-axial shortening behaviour obtained from both the FEA and experimental

2 results is plotted in Fig. 22, which showed good agreement between FEA and test results.

\section{Design rules in accordance with the AISI \& AS/NZS}

4

$$
P_{D 1}=\min \left(P_{n e}, P_{n l}, P_{n d}\right)
$$

The equations for calculating the axial strength for flexural buckling $\left(P_{\mathrm{ne}}\right)$ in AISI [24] are

17 shown as below:

18

$$
\text { For } \lambda_{c} \leq 1.5, P_{n e}=\left(0.658^{\lambda_{c}^{2}}\right) P_{y}
$$

$$
\text { For } \lambda_{c}>1.5, P_{n e}=\left(\frac{0.877}{\lambda_{c}^{2}}\right) P_{y}
$$


1 The nominal axial strength for local buckling $\left(P_{\mathrm{nl}}\right)$ can be calculated by the following 2 equations:

3

$$
\text { For } \lambda_{l} \leq 0.776, P_{n l}=P_{n e}
$$

4

$$
\text { For } \lambda_{l}>0.776, P_{n l}=\left[1-0.15\left(\frac{P_{c r l}}{P_{n e}}\right)^{0.4}\right]\left(\frac{P_{c r l}}{P_{n e}}\right)^{0.4} P_{n e}
$$

5 The nominal axial strength for distortional buckling $\left(P_{\mathrm{nd}}\right)$ can be calculated by the following 6 equations:

7

$$
\text { For } \lambda_{d} \leq 0.561, P_{n d}=P_{y}
$$

8

$$
\text { For } \lambda_{d}>0.561, \quad P_{n d}=\left[1-0.25\left(\frac{P_{c r d}}{P_{y}}\right)^{0.6}\right]\left(\frac{P_{c r d}}{P_{y}}\right)^{0.6} P_{y}
$$

9 Where,

10

$$
\lambda_{c}=\sqrt{\frac{P_{y}}{P_{c r e}}} \quad \lambda_{1}=\sqrt{\frac{P_{n e}}{P_{c r l}}} \quad \lambda_{d}=\sqrt{\frac{P_{y}}{P_{c d}}}, P_{y}=A_{g} f_{y}, P_{c r l}=A_{g} f_{c r l} P_{c r d}=A_{g} f_{c r d}
$$

11 In the above equations, $A_{\mathrm{g}}$ is the gross cross-sectional area. $P_{\text {crl }}, P_{\text {crd }}$ and $P_{\text {cre }}$ are the elastic

12 local, distortional and overall buckling load, respectively, which were calculated by the 13 signature curves using the THIN-WALL-2 [37] software. 
Moen and Schafter [3,4,38,39] proposed modified DSM method for CFS members with unstiffened web openings and it has been adopted in AISI [24] and AS/NZS [25].

It was found by Moen and Schafter [3,4,38,39] that for members with unstiffened web openings, the elastic overall buckling stress is predicted with an approximate "weighted average" of cross-sectional properties The elastic distortional buckling load $\left(P_{\text {crd }}\right)$ was calculated based on the concept of reduced thickness. To calculate the $P_{\text {crd }}$ including the influence of unstiffened web openings, the DSM was used in THIN-WALL-2 [37] software with gross cross-sections to obtain the distortional half-wavelength $\left(L_{\mathrm{crd}}\right)$. After that another finite strip analysis was performed using the modified thickness. The elastic local buckling stress for members with unstiffened web openings was determined from AS/NZS [25].

To obtain the un-factored design strength $\left(P_{\mathrm{D} 1}\right)$ for members with unstiffened web openings, the elastic buckling load was then used in the existing DSM equations as given in Eqs (4)-(9) [25]

Table 4 shows a comparison of the test results $\left(P_{\mathrm{EXP}}\right)$ with the value obtained from DSM $\left(P_{\mathrm{DSM}}\right)$ for $\mathrm{C} 190 \times 45 \times 15$ and $\mathrm{C} 240 \times 45 \times 15$ channel sections. The mean values of the $P_{\mathrm{EXP}} / P_{\mathrm{DSM}}$ ratio are 1.22 and 1.04 for $\mathrm{C} 190 \times 45 \times 15$ and $\mathrm{C} 240 \times 45 \times 15$ channel sections, respectively.

\section{Parametric study}

A parametric study was conducted using validated FE models. The parametric study considered the $\mathrm{C} 190 \times 45 \times 15$ channel sections having an opening diameter of $90 \mathrm{~mm}$ (for both the edge-stiffened and unstiffened web openings), covering columns length from $810 \mathrm{~mm}$ to $2970 \mathrm{~mm}$. The slenderness of column $\left(\lambda_{c}\right)$ ranged from 0.59 to 2.29. Two different opening 
1 spacings were considered: a smaller spacing of $180 \mathrm{~mm}$ and a larger spacing $540 \mathrm{~mm}$. The ratio

2 of opening spacing to web height $(s / d)$ is 0.95 and 2.84 . Furthermore, the parametric study also

3 considered channel sections having edge-stiffened web openings, unstiffened web openings

4 and no web openings (i.e. plain channel sections). The results are presented in Table 5.

Figs. 23 and 24 show the variation of compression resistance against column length and non-dimensional slenderness, respectively. For reference, the experimental points for the CFS channel sections are also shown in Figs. 23 and 24 (even though the opening diameter and spacing was slightly different). Also shown in Figs. 23 and 24, the DSM results for compression resistance of the channel sections without web openings and with unstiffened web openings [24-25].

The effect of opening spacing and the ratio of opening spacing to the web height $(s / d)$ was investigated in the parametric study. As can be seen from Fig. 23, for the case of C190 $\times 45 \times 15-\mathrm{L} 1350-\mathrm{EH}$, when " $s / d$ " changed from 0.95 to 2.84 , the compression resistance was reduced by approximately $12 \%$. For specimens with edge-stiffened web openings, there was an enhancement in compression resistance when " $s / d$ " was 0.95 and 2.84 , compared to that of the plain channel-section. It was shown that for the case of a channel section with edgestiffened web openings having " $s / d$ " as 0.95 , the compression resistance increased by approximately $30 \%$, compared to that of the plain channel sections.

As can be seen from Fig. 23 and Fig. 24, the DSM results were conservative for channel sections without web opening and with unstiffened web openings.

\section{Conclusions}

A detailed experimental and numerical investigation on the compression resistance of CFS channel sections with edge-stiffened web openings was presented in this paper. A total of 75 results comprising 26 tests and 49 finite element analysis results were reported. The material 
properties were determined from the tensile coupon tests and the initial imperfections were measured using a laser scanner. The failure modes, load-axial shortening, load-lateral displacement and load-strain relationship were discussed. The effect of the column length and opening spacing was investigated. Based on the experimental and numerical results presented in this paper, the following conclusions can be drawn:

(1) The test results showed that for the case of CFS channel sections having edge-stiffened web openings, the compression resistance was higher than the plain channel sections. For the case of a channel section having seven edge-stiffened web openings, the compression resistance was increased by as much as $21 \%$, compared to that of the plain channel section. The same section with unstiffened web openings had a $20 \%$ reduction in compression resistance when its performance was compared to that of the plain channel section.

(2) A nonlinear finite element model was developed, which included material nonlinearity and geometric imperfections. The finite element model was validated against the test results, which showed good agreement in terms of failure loads and deflected shapes.

(3) Using the validated finite element models, a parametric study was conducted to investigate the effect of the opening spacing and the column slenderness on the compression resistance. The compression resistance obtained from the FE analysis was compared against the design strengths calculated using the Direct Strength Method. It was found that the DSM was conservative by around $34.5 \%$ for plane channel sections with no web openings which failed through global buckling or a combination of local and global buckling 


\section{Acknowledgement}

2

The authors would like to acknowledge the support of "Howick NZ. Ltd." for providing

3 the test specimens. The experimental work was carried out in "Structures test hall", the

4 department of Civil and Environmental Engineering, the University of Auckland. The

5 contribution of Mark Byrami, Jan Offenberg and Steffen Sake in helping to set up the tests is

6 greatly appreciated. The financial support provided by the China Council Scholarship (CSC)

7 from the Chinese government is greatly acknowledged. 


\section{References}

[1] M.P. Kulatunga, M. Macdonald, Investigation of cold-formed steel structural members with perforations of different arrangements subjected to compression loading, ThinWalled Struct. 67 (2013) 78-87.

[2] M.P. Kulatunga, M. Macdonald, J. Rhodes, D. K. Harrison, Load capacity of cold-formed column members of lipped channel cross-section with perforations subjected to compression loading - Part I: FE simulation and test results, Thin-Walled Struct. 80 (2014) $1-12$.

[3] C.D. Moen, B.W. Schafer, Experiments on cold-formed steel columns with holes, ThinWalled Struct. 46 (2008) 1164-1182.

[4] C.D. Moen, B.W. Schafer, Direct strength method for design of cold-formed steel columns with holes, J. Struct. Eng. 137(5) (2011) 559-570.

[5] A. Uzzaman, J.B.P. Lim, D. Nash, J. Rhodes, B. Young, Web crippling behaviour of coldformed steel channel sections with offset web holes subjected to interior-two-flange loading, Thin-Walled Struct. 50 (2012) 76-86.

[6] A. Uzzaman, J.B.P. Lim, D. Nash, J. Rhodes, B. Young, Cold-formed steel sections with web openings subjected to web crippling under two-flange loading conditions - Part I: tests and finite element analysis, Thin-Walled Struct. 56 (2012) 38-48.

[7] A. Uzzaman, J.B.P. Lim, D. Nash, J. Rhodes, B. Young, Cold-formed steel sections with web openings subjected to web crippling under two-flange loading conditions - Part II: parametric study and proposed design equations, Thin-Walled Struct. 56 (2012) 79-87. 
[8] A. Uzzaman, J.B.P. Lim, D. Nash, J. Rhodes, B. Young, Effect of offset web holes on web crippling strength of cold-formed steel channel sections under end-two-flange loading condition, Thin-Walled Struct. 65 (2013) 34-48.

[9] Y. Lian, A. Uzzaman, J.B.P. Lim, G. Abdelal, D. Nash, B. Young, Effect of web holes on web crippling strength of cold-formed steel channel sections under end-one-flange loading condition - Part I: tests and finite element analysis, Thin-Walled Struct. 107 (2016) 443452.

[10] Y. Lian, A. Uzzaman, J.B.P. Lim, G. Abdelal, D. Nash, B. Young, Effect of web holes on web crippling strength of cold-formed steel channel sections under end-one-flange loading condition - Part II: parametric study and proposed design equations, Thin-Walled Struct. 107 (2016) 489-501.

[11] Y. Lian, A. Uzzaman, J.B.P. Lim, G. Abdelal, D. Nash, B. Young, Web crippling behaviour of cold-formed steel channel sections with web holes subjected to interior-oneflange loading condition - Part I: experimental and numerical investigation, Thin-Walled Struct. 111(2017) 103-112.

[12]Y. Lian, A. Uzzaman, J.B.P. Lim, G. Abdelal, D. Nash, B. Young, Web crippling behaviour of cold-formed steel channel sections with web holes subjected to interior-oneflange loading condition - part II: parametric study and proposed design equations, ThinWalled Struct. 114 (2017) 92-106.

[13] C.H. Pham, Shear buckling of plates and thin-walled channel sections with holes, J. Constr. Steel Res. 128 (2017) 800-811. 
[14] S.H. Pham, C.H. Pham, G.J. Hancock, Direct strength method of design for channel sections in shear with square and circular web holes, J. Struct. Eng. 143(6) (2017) 04017017.

[15] P. Keerthan, M. Mahendran, Improved shear design rules for lipped channel beams with web openings, J. Constr. Steel Res. 97 (2014) 127-142.

[16] P. Keerthan, M. Mahendran, Experimental studies of the shear behaviour and strength of lipped channel beams with web openings, Thin-Walled Struct. 73 (2013) 131-144.

[17] T.G. Singh, K.D. Singh, Experimental investigation on performance of perforated coldformed steel tubular stub columns, Thin-Walled Struct. 131 (2018) 107-121.

[18]N.T. Yu, B. Kim, W.B. Yuan, L.Y. Li and F. Yu, An analytical solution of distortional buckling resistance of cold-formed steel channel-section beams with web openings, ThinWalled Struct. 135 (2019) 446-452.

[19] J.Y. Zhao, K. Sun, C. Yu and J. Wang, Tests and direct strength design on cold-formed steel channel beams with web holes, Eng. Struct. 184 (2019) 434-446.

[20] Howick. Floor joist system. Auckland, New Zealand, 2013.

[21] C. Yu, Cold-formed steel flexural member with edge stiffened web openings: behavior, optimization, and design, J. Constr. Steel Res. 71 (2012) 210-218.

[22] C.N. Grey, C.D. Moen, Elastic buckling simplified methods for cold-formed columns and beams with edge-stiffened holes, Proceedings of the Annual Stability Conference Structural Stability Research Council Pittsburgh. May 10-14 (2011) Pennsylvania, USA. 
[23]A. Uzzaman, J.B.P. Lim, D. Nash, B. Young, Effects of edge-stiffened circular web openings on the web crippling strength of cold-formed steel channel sections under oneflange loading conditions, Eng. Struct. 139 (2017) 96-107.

[24] American Iron and Steel Institute (AISI). North American Specification for the Design of Cold-formed Steel Structural Members AISI S100-16; 2016.

[25] Australia/New Zealand Standard (AS/NZS). Cold-Formed Steel Structures, AS/NZS 4600:2018. Standards Australia/ Standards New Zealand; 2018.

[26] BS EN, Tensile Testing of Metallic Materials Method of Test at Ambient Temperature, British Standards Institution, 2001.

[27] K. Roy, C. Mohammadjani, J.B.P. Lim, Experimental and numerical investigation into the behaviour of face-to-face built-up cold-formed steel channel sections under compression, Thin-Walled Struct. 134 (2019) 291-309.

[28] J. Ye, I. Hajirasouliha, J. Becque, Experimental investigation of local-flexural interactive buckling of cold-formed steel channel columns, Thin-Walled Struct. 125 (2018) 245-258.

[29] J. Ye, S.M. Mojtabaei, I. Hajirasouliha, Local-flexural interactive buckling of standard and optimised cold-formed steel columns, J. Constr. Steel Res. 144 (2018) 106-118.

[30] ABAQUS Analysis User's Manual-Version 6.14-2, ABAQUS Inc., USA, 2018.

[31] T.C.H. Ting, Krishanu Roy, H.H. Lau, J.B.P. Lim, Effect of screw spacing on behavior of axially loaded back-to-back cold-formed steel built-up channel sections, Adv. Struct. Eng. 21 (2018) 474-487. 
[32] K. Roy, T.C.H. Ting, H.H. Lau, J.B.P. Lim, Nonlinear behavior of axially loaded backto-back built-up cold-formed steel un-lipped channel sections, Steel Compos. Struct. 28(2) (2018) 233-250.

[33] K. Roy, T.C.H. Ting, H.H. Lau, and J.B.P. Lim. Experimental investigation into the behaviour of back-to-back gapped built-up cold-formed steel channel sections under compression, in: Proceedings of the 'Wei-Wen Yu International Specialty Conference on Cold-Formed Steel Structures 2018, 7-8 November, 2018, St. Louis, Missouri, USA.

[34] K. Roy, T.C.H. Ting, H.H. Lau, J.B.P. Lim, Nonlinear behavior of back-to-back gapped built-up cold-formed steel channel sections under compression, J. Constr. Steel Res. 147 (2018) 257-276.

[35]E. Ellobody, B. Young, Behavior of cold-formed steel plain angle columns, J. Struct. Eng. $131(2005)$ 457-466.

[36]B. Young, E. Ellobody. Buckling analysis of cold-formed steel lipped angle columns, J. Struct. Eng. 131 (10) (2005) 1570-1579.

[37] V.V. Nguyen, C.H. Pham, G. Hancock, THIN-WALL-2. The University of Sydney, Australia.

[38]C.D. Moen. Direct strength design of cold-formed steel members with perforations. Baltimore: Johns Hopkins University; 2008.

[39] C.D. Moen, B.W. Schafer, Elastic buckling of cold-formed steel columns and beams with holes. Eng Struct 31 (2009) 2812-2824. 


\section{List of tables}

Table 1 Measured specimens dimensions and experimental ultimate loads

Table 2 Material properties obtained from tensile coupon tests

Table 3 Maximum amplitude of local, distortional and overall imperfections

Table 4 Comparisons of ultimate load between numerical, experimental, and theoretical investigations

Table 5 Compression resistance of CFS channel sections with varying opening spacing and lengths from the FE analysis 
Table 1 Measured specimen dimensions and experimental ultimate loads

a) $\mathrm{C} 190 \times 45 \times 15$

(i) $750 \mathrm{~mm}$ length

\begin{tabular}{|c|c|c|c|c|c|c|c|c|c|c|c|}
\hline Specimen & $\begin{array}{c}\text { Web } \\
d \\
(\mathrm{~mm})\end{array}$ & $\begin{array}{c}\text { Flange } \\
b_{f} \\
(\mathrm{~mm})\end{array}$ & $\begin{array}{c}\text { Lip } \\
b_{l} \\
(\mathrm{~mm})\end{array}$ & $\begin{array}{c}\text { Length } \\
\quad L \\
(\mathrm{~mm})\end{array}$ & $\begin{array}{c}\text { Thickness } \\
t \\
(\mathrm{~mm})\end{array}$ & $\begin{array}{l}\text { Stiffener } \\
\quad q \\
(\mathrm{~mm})\end{array}$ & $\begin{array}{c}\text { Dia } \\
a \\
(\mathrm{~mm}\end{array}$ & $\begin{array}{c}\text { Opening spacing } \\
s \\
(\mathrm{~mm})\end{array}$ & $\begin{array}{c}\text { Opening number } \\
n \\
(\mathrm{~mm})\end{array}$ & $\begin{array}{c}\text { Exp. load } \\
P_{\text {EXP }} \\
(\mathrm{kN})\end{array}$ & $\begin{array}{c}\text { Percentage of strength } \\
\text { change due to opening } \\
(\%)\end{array}$ \\
\hline \multicolumn{12}{|l|}{ Plain section } \\
\hline \multicolumn{12}{|c|}{ Edge-stiffened web opening } \\
\hline C190×45×15-L750-EH1 & 190.2 & 44.3 & 15.1 & 752.5 & 1.50 & 13 & 97.5 & - & 1 & 78.8 & +4.2 \\
\hline \multicolumn{12}{|l|}{ Unstiffened web opening } \\
\hline
\end{tabular}

(ii) $1300 \mathrm{~mm}$ length

\begin{tabular}{|c|c|c|c|c|c|c|c|c|c|c|c|}
\hline Specimen & $\begin{array}{c}\text { Web } \\
d \\
(\mathrm{~mm})\end{array}$ & $\begin{array}{c}\text { Flange } \\
b_{f} \\
(\mathrm{~mm})\end{array}$ & $\begin{array}{c}\text { Lip } \\
b_{l} \\
(\mathrm{~mm})\end{array}$ & $\begin{array}{l}\text { Length } \\
\quad L \\
(\mathrm{~mm})\end{array}$ & $\begin{array}{c}\text { Thickness } \\
t \\
(\mathrm{~mm})\end{array}$ & $\begin{array}{l}\text { Stiffener } \\
\quad q \\
(\mathrm{~mm})\end{array}$ & $\begin{array}{c}\text { Dia } \\
a \\
(\mathrm{~mm}\end{array}$ & $\begin{array}{c}\text { Opening spacing } \\
s \\
(\mathrm{~mm})\end{array}$ & $\begin{array}{c}\text { Opening number } \\
n \\
(\mathrm{~mm})\end{array}$ & $\begin{array}{c}\text { Exp. load } \\
P_{\text {EXP }} \\
(\mathrm{kN})\end{array}$ & $\begin{array}{l}\text { Percentage of strength } \\
\text { change due to opening } \\
(\%)\end{array}$ \\
\hline \multicolumn{12}{|l|}{ Plain section } \\
\hline C190×45×15-L1300-NH0 & 189.5 & 44.8 & 15.2 & 1303.9 & 1.41 & - & - & - & - & 59.7 & - \\
\hline \multicolumn{12}{|l|}{ Edge-stiffened web opening } \\
\hline C190×45×15-L1300-EH1 & 189.6 & 44.8 & 15.2 & 1301.5 & 1.48 & 13 & 97.0 & - & 1 & 64.9 & +8.7 \\
\hline \multicolumn{12}{|l|}{ Unstiffened web opening } \\
\hline C190×45×15-L1300-UH1 & 191.5 & 44.9 & 15.1 & 1301.8 & 1.43 & - & 90.8 & - & 1 & 54.2 & -9.1 \\
\hline
\end{tabular}

(iii) $1500 \mathrm{~mm}$ length

\begin{tabular}{|c|c|c|c|c|c|c|c|c|c|c|c|}
\hline Specimen & $\begin{array}{c}\mathrm{Web} \\
d \\
(\mathrm{~mm})\end{array}$ & $\begin{array}{c}\text { Flange } \\
b_{f} \\
(\mathrm{~mm})\end{array}$ & $\begin{array}{c}\text { Lip } \\
b l \\
(\mathrm{~mm})\end{array}$ & $\begin{array}{l}\text { Length } \\
\quad L \\
(\mathrm{~mm})\end{array}$ & $\begin{array}{c}\text { Thickness } \\
t \\
(\mathrm{~mm})\end{array}$ & $\begin{array}{l}\text { Stiffener } \\
\quad q \\
(\mathrm{~mm})\end{array}$ & $\begin{array}{c}\text { Dia } \\
a \\
(\mathrm{~mm}\end{array}$ & $\begin{array}{c}\text { Opening spacing } \\
s \\
(\mathrm{~mm})\end{array}$ & $\begin{array}{c}\text { Opening number } \\
n \\
(\mathrm{~mm})\end{array}$ & $\begin{array}{c}\text { Exp. load } \\
P_{\text {EXP }} \\
(\mathrm{kN})\end{array}$ & $\begin{array}{c}\text { Percentage of strength } \\
\text { change due to opening } \\
(\%)\end{array}$ \\
\hline \multicolumn{12}{|l|}{ Plain section } \\
\hline C190×45×15-L1500-NH0 & 189.0 & 44.5 & 14.5 & 1502.8 & 1.43 & - & - & - & - & 54.9 & - \\
\hline \multicolumn{12}{|l|}{ Edge-stiffened web opening } \\
\hline C190×45×15-L1500-EH1 & 189.5 & 45.6 & 15.9 & 1502.5 & 1.53 & 13 & 97.6 & - & 1 & 60.2 & +9.7 \\
\hline C190×45×15-L1500-EH3 & 191.2 & 45.41 & 15.5 & 1501.8 & 1.52 & 13 & 96.8 & 390 & 3 & 62.3 & +13.5 \\
\hline C190×45×15-L1500-EH5 & 190.0 & 45.0 & 15.8 & 1501.7 & 1.53 & 13 & 97.2 & 290 & 5 & 63.6 & +15.8 \\
\hline C190×45×15-L1500-EH7 & 190.8 & 45.1 & 15.6 & 1501.5 & 1.51 & 13 & 97.5 & 190 & 7 & 66.5 & +22.1 \\
\hline \multicolumn{12}{|l|}{ Unstiffened web opening } \\
\hline C190×45×15-L1500-UH1 & 189.1 & 44.8 & 15.5 & 1502.8 & 1.45 & - & 89.7 & - & 1 & 46.9 & -14.5 \\
\hline C190×45×15-L1500-UH3 & 190.5 & 45.4 & 15.6 & 1501.5 & 1.46 & - & 89.5 & 390 & 3 & 46.1 & -16.0 \\
\hline C190×45×15-L1500-UH5 & 188.9 & 44.9 & 15.0 & 1501.0 & 1.44 & - & 89.9 & 290 & 5 & 44.6 & -18.7 \\
\hline C190×45×15-L1500-UH7 & 189.0 & 44.4 & 15.8 & 1502.5 & 1.45 & - & 90.3 & 190 & 7 & 43.8 & -20.2 \\
\hline
\end{tabular}

b) $C 240 \times 45 \times 15$

\begin{tabular}{|c|c|c|c|c|c|c|c|c|c|c|c|}
\hline Specimen & $\begin{array}{c}\text { Web } \\
d \\
(\mathrm{~mm})\end{array}$ & $\begin{array}{c}\text { Flange } \\
b_{f} \\
(\mathrm{~mm})\end{array}$ & $\begin{array}{c}\text { Lip } \\
b l \\
(\mathrm{~mm})\end{array}$ & $\begin{array}{l}\text { Length } \\
\quad L \\
(\mathrm{~mm})\end{array}$ & $\begin{array}{c}\text { Thickness } \\
t \\
(\mathrm{~mm})\end{array}$ & $\begin{array}{l}\text { Stiffener } \\
\qquad \begin{array}{l}q \\
(\mathrm{~mm})\end{array}\end{array}$ & $\begin{array}{c}\text { Dia } \\
a \\
(\mathrm{~mm})\end{array}$ & $\begin{array}{c}\text { Opening spacing } \\
s \\
(\mathrm{~mm})\end{array}$ & $\begin{array}{c}\text { Opening number } \\
n \\
(\mathrm{~mm})\end{array}$ & $\begin{array}{c}\text { Exp.load } \\
P_{\text {EXP }} \\
(\mathrm{kN})\end{array}$ & $\begin{array}{l}\text { Percentage of strength } \\
\text { change due to opening } \\
(\%)\end{array}$ \\
\hline \multicolumn{12}{|l|}{ Plain section } \\
\hline C240×45×15-L1500-NH0-1 & 239.0 & 44.6 & 15.5 & 1505.8 & 1.75 & - & - & - & - & 62.3 & - \\
\hline C240×45×15-L1500-NH0-2 & 240.5 & 44.2 & 14.8 & 1502.5 & 1.74 & - & - & - & - & 59.5 & - \\
\hline $\mathrm{C} 240 \times 45 \times 15-\mathrm{L} 1500-\mathrm{NH} 0-3$ & 238.5 & 44.9 & 14.7 & 1500.1 & 1.79 & - & - & - & - & 60.8 & - \\
\hline \multicolumn{12}{|l|}{ Edge-stiffened web opening } \\
\hline C240×45×15-L1500-EH1 & 238.0 & 45.7 & 15.0 & 1502.0 & 1.75 & 13 & 143.7 & - & 1 & 63.9 & +4.9 \\
\hline C240×45×15-L1500-EH3 & 239.5 & 44.9 & 14.7 & 1502.5 & 1.72 & 13 & 142.7 & 390 & 3 & 66.0 & +8.5 \\
\hline C240×45×15-L1500-EH5 & 238.5 & 44.7 & 14.5 & 1501.5 & 1.73 & 13 & 143.5 & 290 & 5 & 68.0 & +11.6 \\
\hline C240×45×15-L1500-EH7 & 239.5 & 43.5 & 15.4 & 1501.8 & 1.70 & 13 & 140.5 & 190 & 7 & 73.2 & +20.1 \\
\hline \multicolumn{12}{|l|}{ Unstiffened web opening } \\
\hline C240×45×15-L1500-UH1 & 239.5 & 44.2 & 15.6 & 1502.0 & - & - & 145.2 & - & 1 & 52.1 & -14.5 \\
\hline C240×45×15-L1500-UH3 & 238.2 & 44.8 & 15.2 & 1502.1 & 1.71 & - & 127.2 & 390 & 3 & 49.4 & -18.9 \\
\hline C240×45×15-L1500-UH5 & 240.7 & 44.7 & 15.6 & 1501.2 & 1.70 & - & 130.2 & 290 & 5 & 48.2 & -20.8 \\
\hline C240×45×15-L1500-UH7 & 239.7 & 44.6 & 14.8 & 1502.3 & 1.73 & - & 130.5 & 190 & 7 & 47.3 & -22.4 \\
\hline
\end{tabular}


Table 2 Material properties obtained from coupon tests

\begin{tabular}{lccc}
\hline Section & Thickness & Yield stress & Ultimate stress \\
& $t$ & $\sigma_{0.2}$ & $\sigma_{\mathrm{u}}$ \\
& $\mathrm{mm}$ & $\mathrm{MPa}$ & $\mathrm{MPa}$ \\
\hline $240 \times 45 \times 15$ & 1.75 & 309.31 & 377.78 \\
$190 \times 45 \times 15$ & 1.49 & 285.17 & 379.35 \\
\hline
\end{tabular}


Table 3 Maximum amplitude of local, distortional and overall imperfections

\begin{tabular}{|c|c|c|c|}
\hline Specimen & $\begin{array}{l}\text { Local } \\
(\mathrm{mm})\end{array}$ & $\begin{array}{l}\text { Distortional } \\
(\mathrm{mm})\end{array}$ & $\begin{array}{l}\text { Global } \\
(\mathrm{mm})\end{array}$ \\
\hline $\mathrm{C} 240 \times 45 \times 15-\mathrm{L} 1500-\mathrm{NH} 0-1$ & 0.59 & 1.04 & 0.76 \\
\hline $\mathrm{C} 240 \times 45 \times 15-\mathrm{L} 1500-\mathrm{NH} 0-2$ & 0.36 & 1.02 & 0.29 \\
\hline $\mathrm{C} 240 \times 45 \times 15-\mathrm{L} 1500-\mathrm{NH} 0-3$ & 0.25 & 1.26 & 0.33 \\
\hline C190×45×15-L1500-NH0 & 0.52 & 1.18 & 0.74 \\
\hline C240×45×15-L1500-UH1 & 0.58 & 1.18 & 0.45 \\
\hline C240×45×15-L1500-UH3 & 0.99 & 0.74 & 0.15 \\
\hline C240×45×15-L1500-UH5 & 0.91 & 0.79 & 0.83 \\
\hline C240×45×15-L1500-UH7 & 0.21 & 1.07 & 0.78 \\
\hline C190×45×15-L1500-UH1 & 0.47 & 0.86 & 0.48 \\
\hline C190×45×15-L1500-UH3 & 0.54 & 0.66 & 0.76 \\
\hline C190×45×15-L1300-NH0 & 0.26 & 0.97 & 0.68 \\
\hline C190×45×15-L750-NH0 & 0.31 & 0.89 & 0.63 \\
\hline C190×45×15-L1300-UH1 & 0.56 & 1.10 & 0.60 \\
\hline C190×45×15-L1500-UH5 & 0.29 & 0.58 & 0.27 \\
\hline C190×45×15-L1500-UH7 & 0.13 & 1.04 & 0.26 \\
\hline C240×45×15-L1500-EH1 & 0.90 & 0.71 & 0.66 \\
\hline C240×45×15-L1500-EH3 & 0.91 & 0.77 & 0.50 \\
\hline C240×45×15-L1500-EH5 & 0.89 & 1.09 & 0.78 \\
\hline C240×45×15-L1500-EH7 & 0.99 & 1.03 & 0.82 \\
\hline C190×45×15-L1500-EH1 & 1.05 & 0.55 & 0.80 \\
\hline C190×45×15-L1500-EH3 & 1.32 & 1.01 & 0.65 \\
\hline C190×45×15-L1500-EH5 & 1.07 & 0.48 & 0.35 \\
\hline C190×45×15-L1500-EH7 & 1.06 & 0.44 & 0.87 \\
\hline C190×45×15-L750-UH1 & 0.56 & 0.95 & 0.79 \\
\hline C190×45×15-L1300-EH1 & 1.13 & 0.87 & 0.35 \\
\hline C190×45×15-L750-EH1 & 1.26 & 0.92 & 0.51 \\
\hline
\end{tabular}


Table 4 Comparisons of ultimate load between numerical, experimental, and theoretical investigations

a) $\mathrm{C} 190 \times 45 \times 15$

(i) $750 \mathrm{~mm}$ length

\begin{tabular}{|c|c|c|c|c|c|}
\hline \multirow{2}{*}{ Specimen } & \multirow{2}{*}{$\begin{array}{c}\text { Exp. results } \\
P_{\text {EXP }} \\
(\mathrm{kN})\end{array}$} & \multirow{2}{*}{$\begin{array}{c}\text { Numerical results } \\
\qquad P_{\mathrm{FEA}} \\
(\mathrm{kN})\end{array}$} & \multirow{2}{*}{$\begin{array}{l}\mathrm{DSM} \\
P_{\mathrm{DSM}}\end{array}$} & \multicolumn{2}{|c|}{ Comparison } \\
\hline & & & & $P_{\mathrm{EXP}} / P_{\mathrm{FEA}}$ & $P_{\mathrm{EXP}} / P_{\mathrm{DSM}}$ \\
\hline \multicolumn{6}{|l|}{ Plain section } \\
\hline C190×45×15-L750-NH0 & 75.65 & 74.55 & 58.30 & 1.01 & 1.29 \\
\hline \multicolumn{6}{|c|}{ Edge-stiffened web opening } \\
\hline C190×45×15-L750-EH1 & 78.83 & 77.63 & - & 1.02 & - \\
\hline \multicolumn{6}{|l|}{ Unstiffened web opening } \\
\hline C190×45×15-L750-UH1 & 60.62 & 62.50 & 49.86 & 0.97 & 1.21 \\
\hline
\end{tabular}

(ii) $1300 \mathrm{~mm}$ length

\begin{tabular}{|c|c|c|c|c|c|}
\hline \multirow{2}{*}{ Specimen } & \multirow{2}{*}{$\begin{array}{c}\text { Exp. results } \\
P_{\text {EXP }} \\
(\mathrm{kN})\end{array}$} & \multirow{2}{*}{$\begin{array}{c}\text { Numerical results } \\
P_{\mathrm{FEA}} \\
(\mathrm{kN})\end{array}$} & \multirow{2}{*}{$\begin{array}{l}\mathrm{DSM} \\
P_{\mathrm{DSM}} \\
(\mathrm{kN})\end{array}$} & \multicolumn{2}{|c|}{ Comparison } \\
\hline & & & & $P_{\mathrm{EXP}} / P_{\mathrm{FEA}}$ & $P_{\mathrm{EXP}} / P_{\mathrm{DSM}}$ \\
\hline \multicolumn{6}{|l|}{ Plain section } \\
\hline C190×45×15-L1300-NH0 & 59.69 & 60.09 & 48.92 & 0.99 & 1.22 \\
\hline \multicolumn{6}{|l|}{ Edge-stiffened web opening } \\
\hline C190×45×15-L1300-EH1 & 64.90 & 65.75 & - & 0.99 & - \\
\hline \multicolumn{6}{|l|}{ Unstiffened web opening } \\
\hline C190×45×15-L1300-UH1 & 54.23 & 54.82 & 42.85 & 0.99 & 1.26 \\
\hline
\end{tabular}

(iii) $1500 \mathrm{~mm}$ length

\begin{tabular}{|c|c|c|c|c|c|}
\hline \multirow{2}{*}{ Specimen } & \multirow{2}{*}{$\begin{array}{c}\text { Exp. results } \\
P_{\text {EXP }} \\
(\mathrm{kN})\end{array}$} & \multirow{2}{*}{$\begin{array}{c}\text { Numerical results } \\
\qquad P_{\mathrm{FEA}} \\
(\mathrm{kN})\end{array}$} & \multirow{2}{*}{$\begin{array}{l}\mathrm{DSM} \\
P_{\mathrm{DSM}} \\
(\mathrm{kN})\end{array}$} & \multicolumn{2}{|c|}{ Comparison } \\
\hline & & & & $P_{\mathrm{EXP}} / P_{\mathrm{FEA}}$ & $P_{\mathrm{EXP}} / P_{\mathrm{DSM}}$ \\
\hline \multicolumn{6}{|l|}{ Plain section } \\
\hline C190×45×15-L1500-NH0 & 54.90 & 53.59 & 44.36 & 1.02 & 1.23 \\
\hline \multicolumn{6}{|l|}{ Edge-stiffened web opening } \\
\hline C190×45×15-L1500-EH1 & 60.19 & 62.30 & - & 0.97 & - \\
\hline C190×45×15-L1500-EH3 & 62.31 & 65.18 & - & 0.96 & - \\
\hline C190×45×15-L1500-EH5 & 63.64 & 66.03 & - & 0.96 & - \\
\hline C190×45×15-L1500-EH7 & 66.47 & 68.39 & - & 0.97 & - \\
\hline \multicolumn{6}{|l|}{ Unstiffened web opening } \\
\hline C190×45×15-L1500-UH1 & 46.87 & 47.12 & 39.61 & 0.99 & 1.18 \\
\hline C190×45×15-L1500-UH3 & 46.13 & 45.63 & 38.38 & 1.01 & 1.20 \\
\hline C190×45×15-L1500-UH5 & 44.62 & 43.64 & 37.14 & 1.02 & 1.20 \\
\hline C190×45×15-L1500-UH7 & 44.07 & 43.59 & 35.89 & 1.01 & 1.22 \\
\hline
\end{tabular}

b) $\mathrm{C} 240 \times 45 \times 15$

\begin{tabular}{|c|c|c|c|c|c|}
\hline \multirow{2}{*}{ Specimen } & \multirow{2}{*}{$\begin{array}{c}\text { Exp. results } \\
P_{\text {EXP }} \\
(\mathrm{kN})\end{array}$} & \multirow{2}{*}{$\begin{array}{c}\text { Numerical results } \\
P_{\mathrm{FEA}} \\
(\mathrm{kN})\end{array}$} & \multirow{2}{*}{$\begin{array}{c}\mathrm{DSM} \\
P_{\mathrm{DSM}} \\
(\mathrm{kN})\end{array}$} & \multicolumn{2}{|c|}{ Comparison } \\
\hline & & & & $P_{\mathrm{EXP}} / P_{\mathrm{FEA}}$ & $P_{\mathrm{EXP}} / P_{\mathrm{DSM}}$ \\
\hline \multicolumn{6}{|l|}{ Plain section } \\
\hline C240×45×15-L1500-NH0-1 & 61.35 & 62.79 & 59.72 & 0.98 & 1.03 \\
\hline $\mathrm{C} 240 \times 45 \times 15-\mathrm{L} 1500-\mathrm{NH} 0-2$ & 59.58 & 61.86 & 59.72 & 0.96 & 1.00 \\
\hline C240×45×15-L1500-NH0-3 & 60.85 & 62.10 & 59.72 & 0.98 & 1.02 \\
\hline \multicolumn{6}{|l|}{ Edge-stiffened web opening } \\
\hline C240×45×15-L1500-EH1 & 63.96 & 63.52 & - & 1.01 & - \\
\hline C240×45×15-L1500-EH3 & 66.09 & 66.78 & - & 0.99 & - \\
\hline C240×45×15-L1500-EH5 & 68.02 & 69.31 & - & 0.98 & - \\
\hline C240×45×15-L1500-EH7 & 73.23 & 72.51 & - & 1.01 & - \\
\hline \multicolumn{6}{|l|}{ Unstiffened web opening } \\
\hline C240×45×15-L1500-UH1 & 52.05 & 51.71 & 49.58 & 1.01 & 1.05 \\
\hline C240×45×15-L1500-UH3 & 49.37 & 49.88 & 47.65 & 0.99 & 1.04 \\
\hline C240×45×15-L1500-UH5 & 48.22 & 49.21 & 45.70 & 0.98 & 1.06 \\
\hline C240×45×15-L1500-UH7 & 47.31 & 48.59 & 43.73 & 0.97 & 1.08 \\
\hline
\end{tabular}


Table 5 Compression resistance of CFS channel sections with varying opening spacing and lengths from the FE analysis

\begin{tabular}{|c|c|c|c|c|c|c|c|c|c|}
\hline Specimen & $\begin{array}{l}\text { Web } \\
d \\
\mathrm{~mm}\end{array}$ & $\begin{array}{l}\text { Flange } \\
\qquad \begin{array}{l}b_{f} \\
\mathrm{~mm}\end{array}\end{array}$ & $\begin{array}{l}\text { Lip } \\
b_{l} \\
\mathrm{~mm}\end{array}$ & $\begin{array}{c}\text { Thickness } \\
t \\
\text { mm }\end{array}$ & $\begin{array}{c}\text { Length of } \\
\text { column } \\
\qquad \begin{array}{c}L \\
\mathrm{~mm}\end{array}\end{array}$ & $\begin{array}{c}\text { Slenderness of } \\
\text { column } \\
\lambda_{c}\end{array}$ & $\begin{array}{c}\text { Opening spacing } \\
s \\
\mathrm{~mm}\end{array}$ & $\begin{array}{c}\text { Ratio of opening spacing } \\
\text { to web height } \\
\text { s/d } \\
\mathrm{mm}\end{array}$ & $\begin{array}{c}\text { Numerical results } \\
P_{\text {FEA }} \\
\text { kN }\end{array}$ \\
\hline \multicolumn{10}{|l|}{ Plain section } \\
\hline C190×45×15-L1890-NH0-S180 & 190 & 45 & 15 & 1.45 & 1890 & 1.37 & - & - & 46.1 \\
\hline C190×45×15-L2000-NH0-S180 & 190 & 45 & 15 & 1.45 & 2000 & 1.45 & - & - & 41.4 \\
\hline C190×45×15-L2300-NH0-S180 & 190 & 45 & 15 & 1.45 & 2300 & 1.67 & - & - & 33.5 \\
\hline C190×45×15-L2430-NH0-S180 & 190 & 45 & 15 & 1.45 & 2430 & 1.77 & - & - & 31.3 \\
\hline C190×45×15-L2970-NH0-S180 & 190 & 45 & 15 & 1.45 & 2970 & 2.16 & - & - & 23.0 \\
\hline \multicolumn{10}{|l|}{ Unstiffened web opening } \\
\hline C190×45×15-L810-UH4-S180 & 190 & 45 & 15 & 1.45 & 810 & 0.59 & 180 & 0.95 & 55.1 \\
\hline C190×45×15-L1350-UH7-S180 & 190 & 45 & 15 & 1.45 & 1350 & 0.98 & 180 & 0.95 & 45.0 \\
\hline C190×45×15-L1890-UH10-S180 & 190 & 45 & 15 & 1.45 & 1890 & 1.37 & 180 & 0.95 & 35.1 \\
\hline C190×45×15-L2430-UH13-S180 & 190 & 45 & 15 & 1.45 & 2430 & 1.77 & 180 & 0.95 & 24.2 \\
\hline C190×45×15-L2970-UH16-S180 & 190 & 45 & 15 & 1.45 & 2970 & 2.16 & 180 & 0.95 & 18.1 \\
\hline \multicolumn{10}{|l|}{ Edge-stiffened web opening } \\
\hline C190×45×15-L810-EH4-S180 & 190 & 45 & 15 & 1.45 & 810 & 0.59 & 180 & 0.95 & 78.2 \\
\hline C190×45×15-L1350-EH7-S180 & 190 & 45 & 15 & 1.45 & 1350 & 0.98 & 180 & 0.95 & 75.1 \\
\hline C190×45×15-L1890-EH10-S180 & 190 & 45 & 15 & 1.45 & 1890 & 1.37 & 180 & 0.95 & 58.5 \\
\hline C190×45×15-L2070-EH11-S180 & 190 & 45 & 15 & 1.45 & 2070 & 1.50 & 180 & 0.95 & 49.8 \\
\hline C190×45×15-L2250-EH12-S180 & 190 & 45 & 15 & 1.45 & 2250 & 1.64 & 180 & 0.95 & 44.3 \\
\hline C190×45×15-L2430-EH13-S180 & 190 & 45 & 15 & 1.45 & 2430 & 1.77 & 180 & 0.95 & 41.1 \\
\hline C190×45×15-L2610-EH14-S180 & 190 & 45 & 15 & 1.45 & 2610 & 1.90 & 180 & 0.95 & 36.4 \\
\hline C190×45×15-L2790-EH15-S180 & 190 & 45 & 15 & 1.45 & 2790 & 2.03 & 180 & 0.95 & 32.7 \\
\hline C190×45×15-L2970-EH16-S180 & 190 & 45 & 15 & 1.45 & 2970 & 2.16 & 180 & 0.95 & 30.5 \\
\hline C190×45×15-L3150-EH17-S180 & 190 & 45 & 15 & 1.45 & 3150 & 2.29 & 180 & 0.95 & 26.3 \\
\hline C190×45×15-L1350-EH3-S540 & 190 & 45 & 15 & 1.45 & 1350 & 0.98 & 540 & 2.84 & 66.3 \\
\hline C190×45×15-L1890-EH4-S540 & 190 & 45 & 15 & 1.45 & 1890 & 1.37 & 540 & 2.84 & 48.2 \\
\hline C190×45×15-L2430-EH5-S540 & 190 & 45 & 15 & 1.45 & 2430 & 1.77 & 540 & 2.84 & 38.3 \\
\hline
\end{tabular}




\section{List of figures}

Fig. 1 Cold-formed steel channel sections

(a) Section with unstiffened web openings

(b) Section with edge-stiffened web openings

Fig. 2 Different opening spacing

Fig. 3 Nominal cross-sections of the CFS channel sections considered in this paper

Fig. 4 Specimen labelling

Fig. 5 Coupon test configuration

Fig. 6 Stress-strain curves;

(a) Section $190 \times 45 \times 15$

(b) Section $240 \times 45 \times 15$

Fig. 7 Test set-up;

(a) Photograph

(b) Schematic drawing

Fig. 8 Photograph of the pin support;

(a) Side view

(b) Vertical view

Fig. 9 Location of strain gauge at mid-height;

(a) Section with web openings

(b) Section without web openings

Fig. 10 Photograph of imperfection measurements setup

Fig. 11 Locations of the imperfection measurements;

(a) Section with web openings

(b) Section without web openings

Fig. 12 Typical imperfection profile (C190×45×15-L1500-EH3);

(a) Imperfection of $\mathrm{W}-2$ and $\mathrm{W}-3$

(b) Imperfection of $\mathrm{W}-1$ and $\mathrm{W}-4$

(c) Imperfection of F-1 and F-2

Fig. 13 Failure modes of $1500 \mathrm{~mm}$ long specimens with unstiffened and edge-stiffened web openings

Fig. 14 Load versus axial shortening curves for specimens with various lengths

Fig. 15 Comparison of load-displacement response for specimens with and without web openings;

Fig. 16 Axial load versus axial shortening curves of specimens with different opening spacing;

(a) Section $190 \times 45 \times 15$

(b) Section $240 \times 45 \times 15$

Fig. 17 Axial load versus lateral displacement relationship at mid-height of specimens;

(a) $\mathrm{C} 240 \times 45 \times 15-\mathrm{L} 1500-\mathrm{UH} 1$

(b) $\mathrm{C} 240 \times 45 \times 15-\mathrm{L} 1500-\mathrm{UH} 3$

(c) $\mathrm{C} 240 \times 45 \times 15-\mathrm{L} 1500-\mathrm{EH} 1$

(d) $\mathrm{C} 240 \times 45 \times 15-\mathrm{L} 1500-\mathrm{EH} 3$

Fig. 18 Axial load versus strain;

(a) $\mathrm{C} 190 \times 45 \times 15-\mathrm{L} 1500-\mathrm{EH} 3$

(b) C190×45×15-L1500-EH5

Fig. 19 Boundary condition and mesh type for C240×45×15-L1500-EH1;

Fig. 20 Initial imperfection contours (C240×45×15-L1500-EH1);

(a) Local buckling

(b) Overall buckling

Fig. 21 Deformed shapes at failure from experiments and FEA;

(a) $\mathrm{C} 240 \times 45 \times 15-\mathrm{L} 1500-\mathrm{EH} 1$

(b) $\mathrm{C} 240 \times 45 \times 15-\mathrm{L} 1500-\mathrm{EH} 3$ 
(c) $\mathrm{C} 240 \times 45 \times 15-\mathrm{L} 1500-\mathrm{EH} 5$

(d) $\mathrm{C} 240 \times 45 \times 15-\mathrm{L} 1500-\mathrm{EH} 7$

Fig. 22 Load versus axial displacement curves from experiments and FEA;
(a) $\mathrm{C} 190 \times 45 \times 15-\mathrm{L} 1500-\mathrm{NH} 0$
(b) $\mathrm{C} 190 \times 45 \times 15-\mathrm{L} 1500-\mathrm{UH} 1$
(c) $\mathrm{C} 190 \times 45 \times 15-\mathrm{L} 1500-\mathrm{UH} 7$
(d) $\mathrm{C} 240 \times 45 \times 15-\mathrm{L} 1500-\mathrm{UH} 1$

Fig. 23 Variation of strength against length for section $190 \times 45 \times 15$;

Fig. 24 Variation of strength against slenderness for section $190 \times 45 \times 15$; 


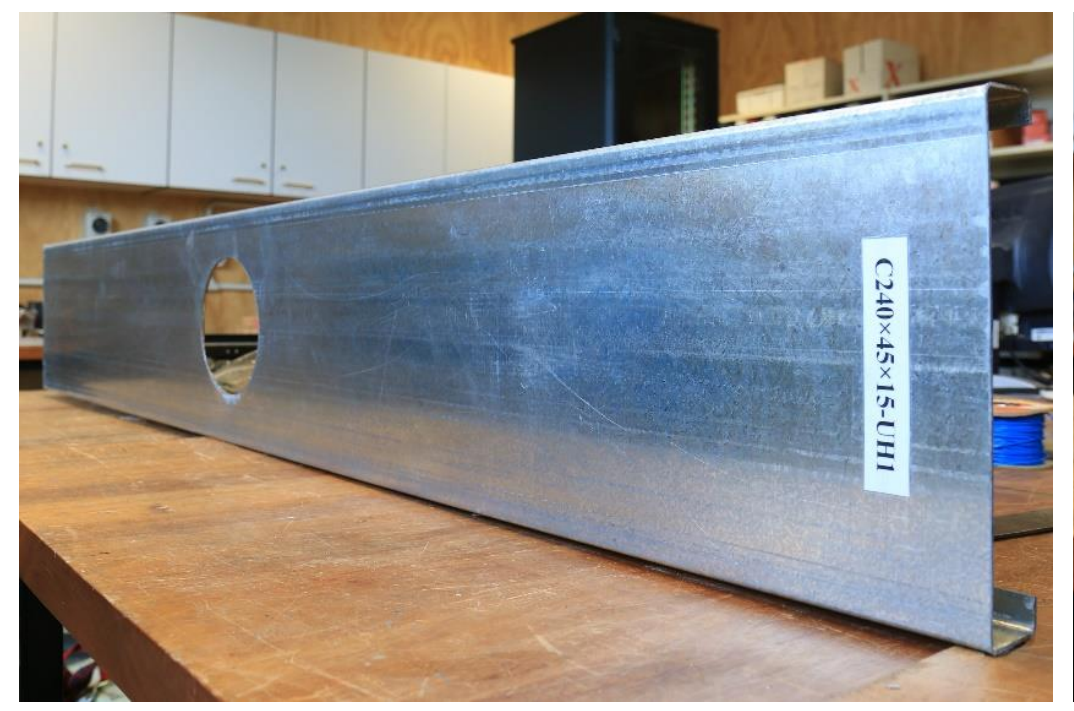

(a) Section with unstiffened web openings

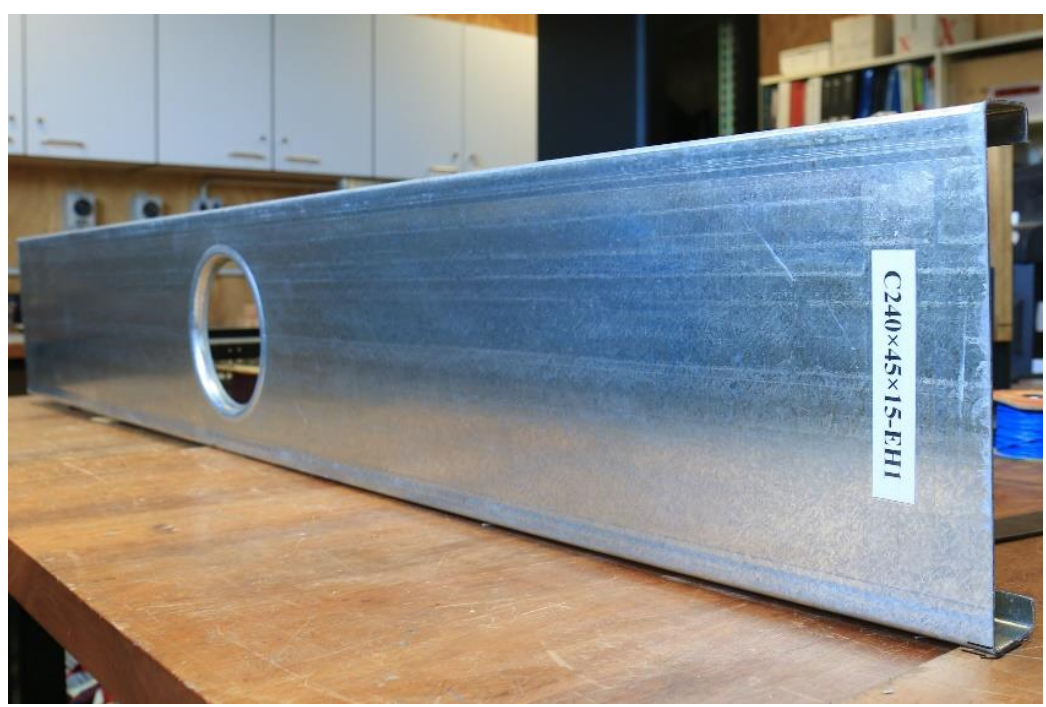

(b) Section with edge-stiffened web openings

Fig. 1 Cold-formed steel channel sections 

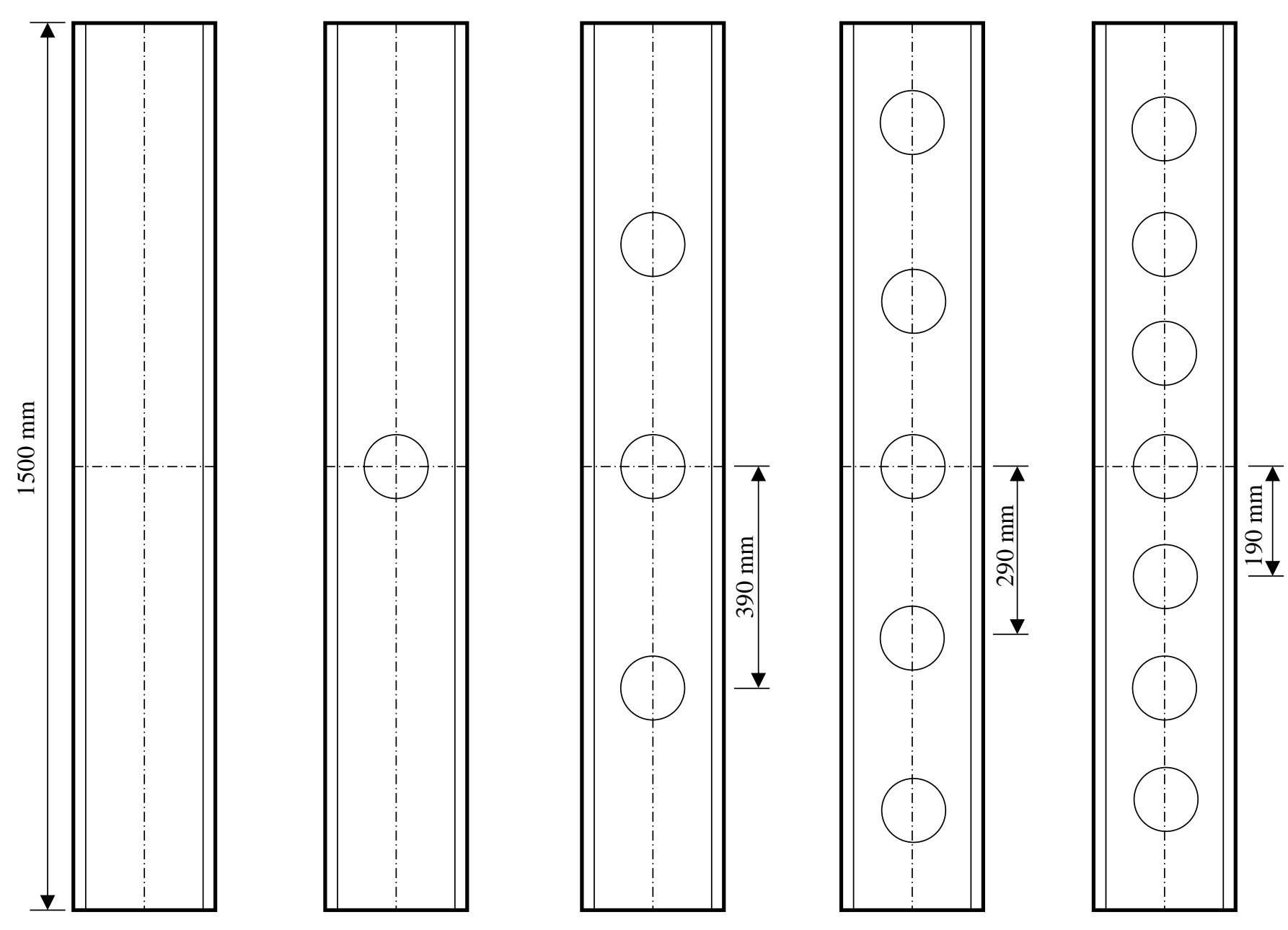

Fig. 2 Different opening spacing 

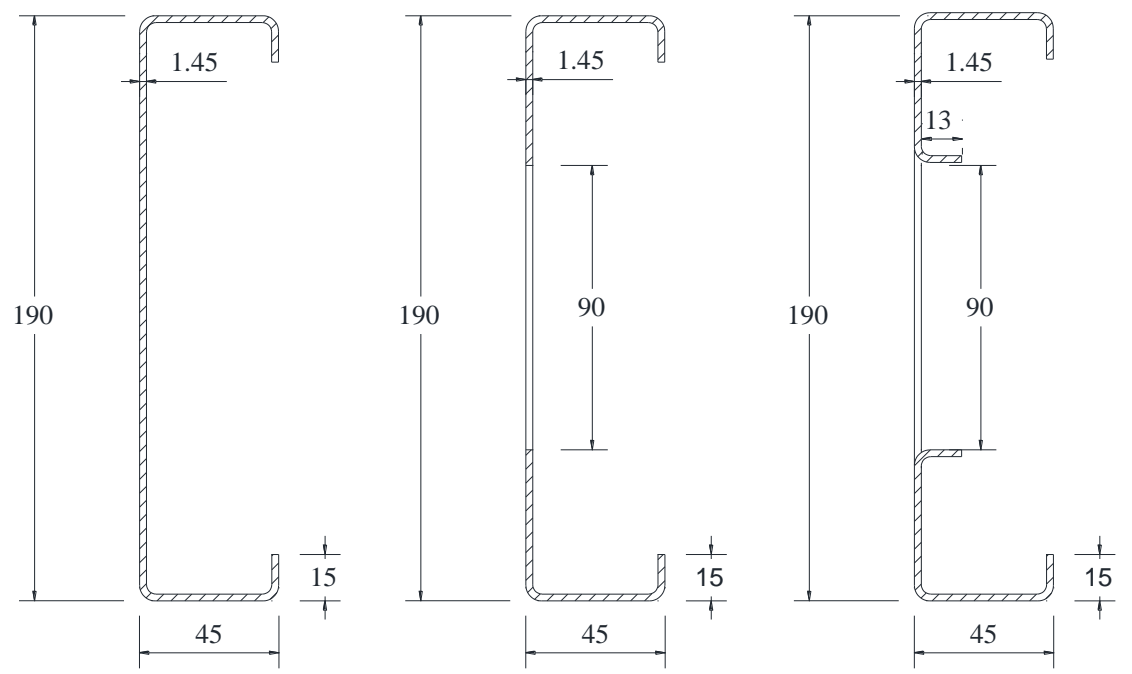

(a) Section $190 \times 45 \times 15$
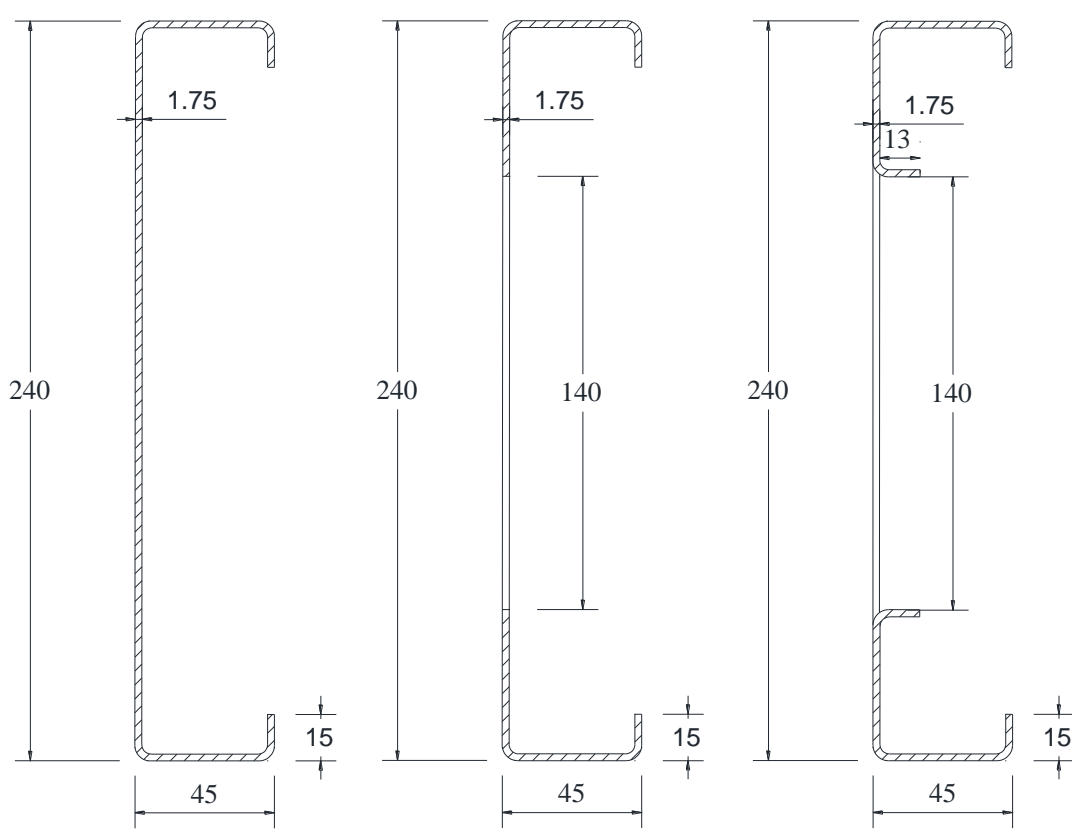

Note: All dimensions are in mm

(b) Section $240 \times 45 \times 15$

Fig. 3 Nominal cross-sections of the CFS channel sections considered in this paper 


\section{Length \\ Specimen 1 \\ C240×45×15-L1500-EH3-1}

Channel section

Web

Flange
Edge-stiffened hole

Number of hole

Fig. 4 Specimen labelling 


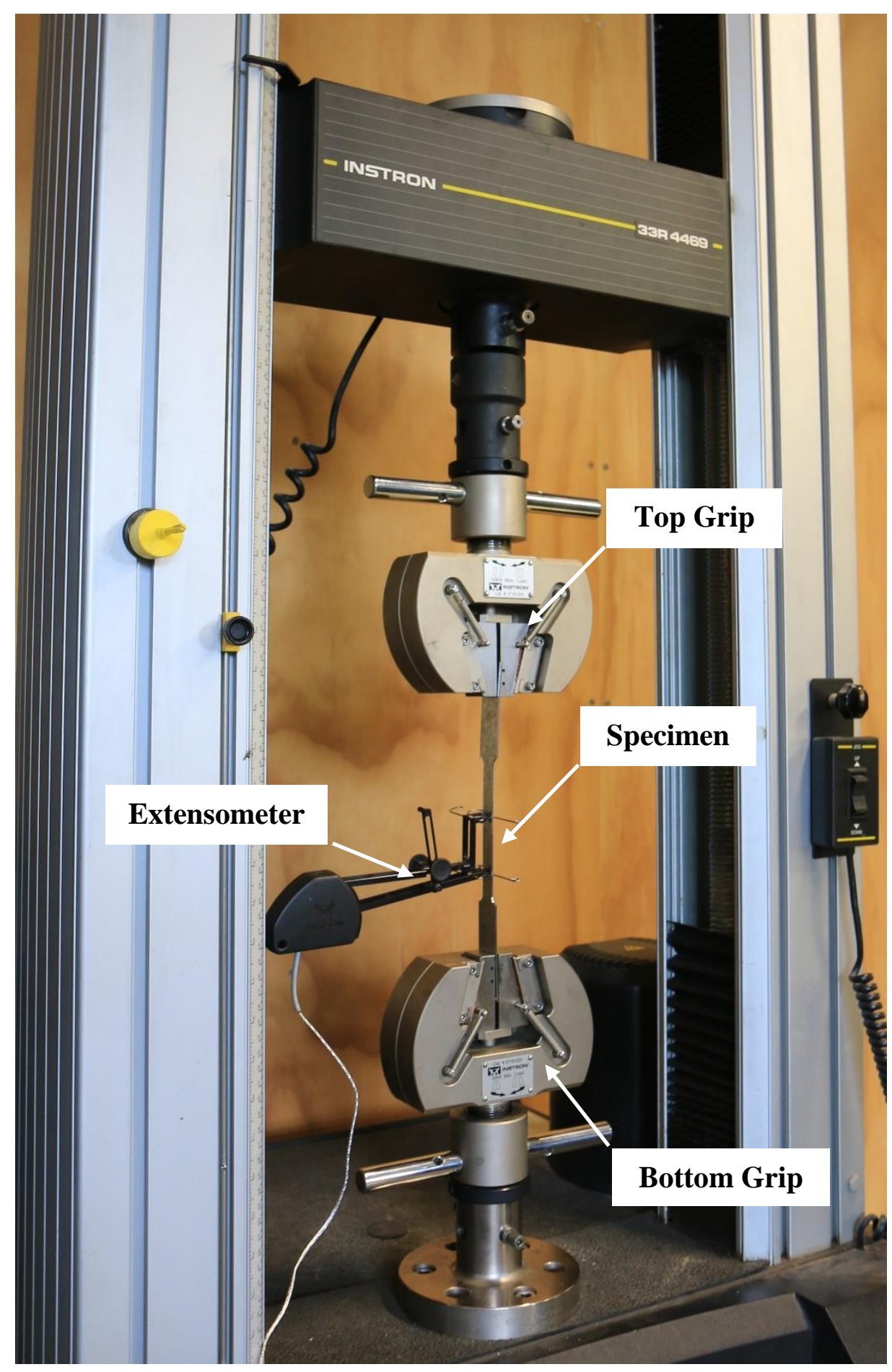

Fig. 5 Coupon test configuration

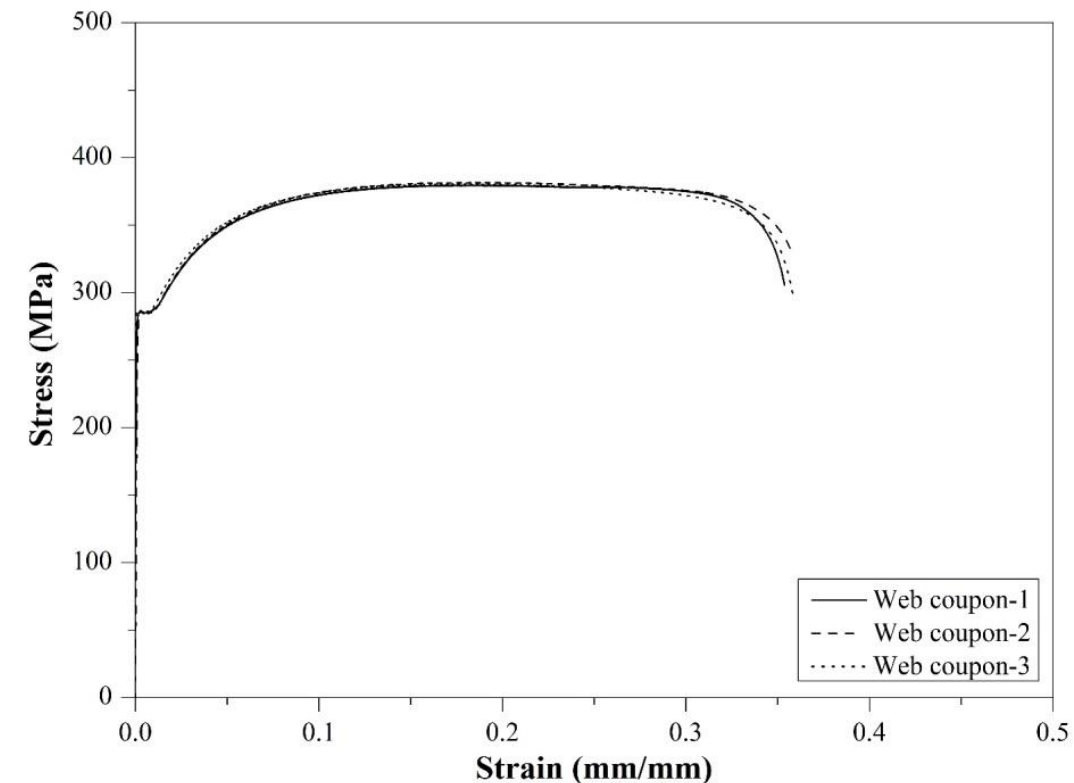

(a) Section $190 \times 45 \times 15$

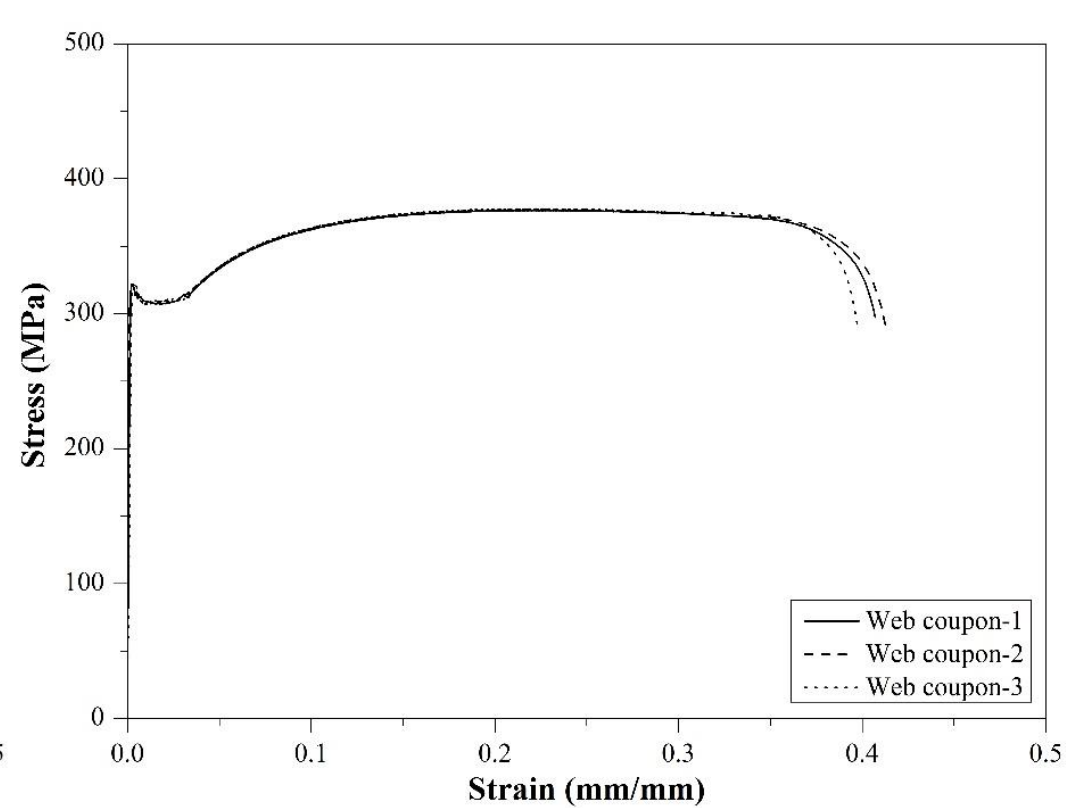

(b) Section $240 \times 45 \times 15$

Fig. 6 Stress-strain curves 


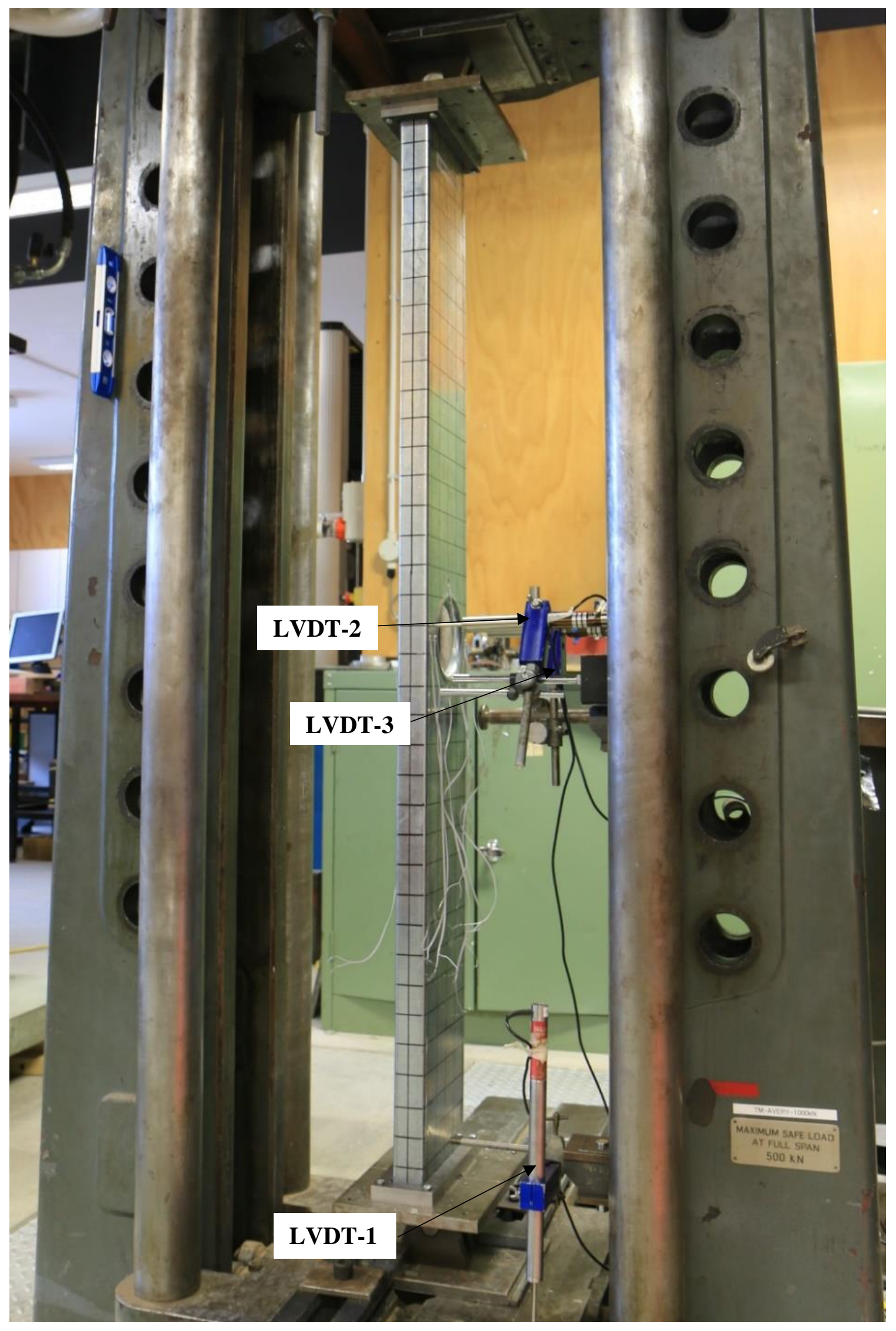

(a) Photograph 


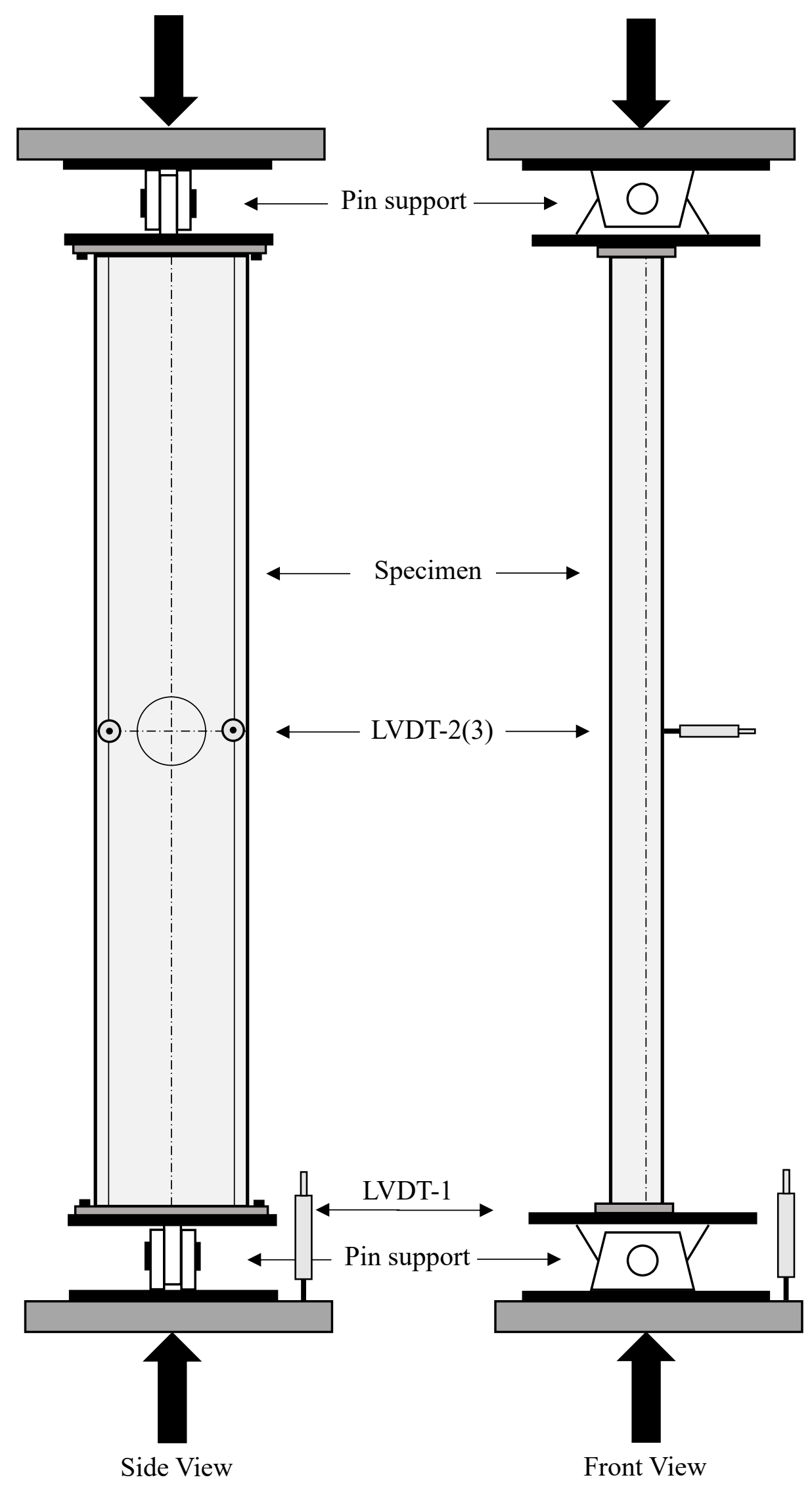

(b) Schematic drawing

Fig. 7 Test set-up 


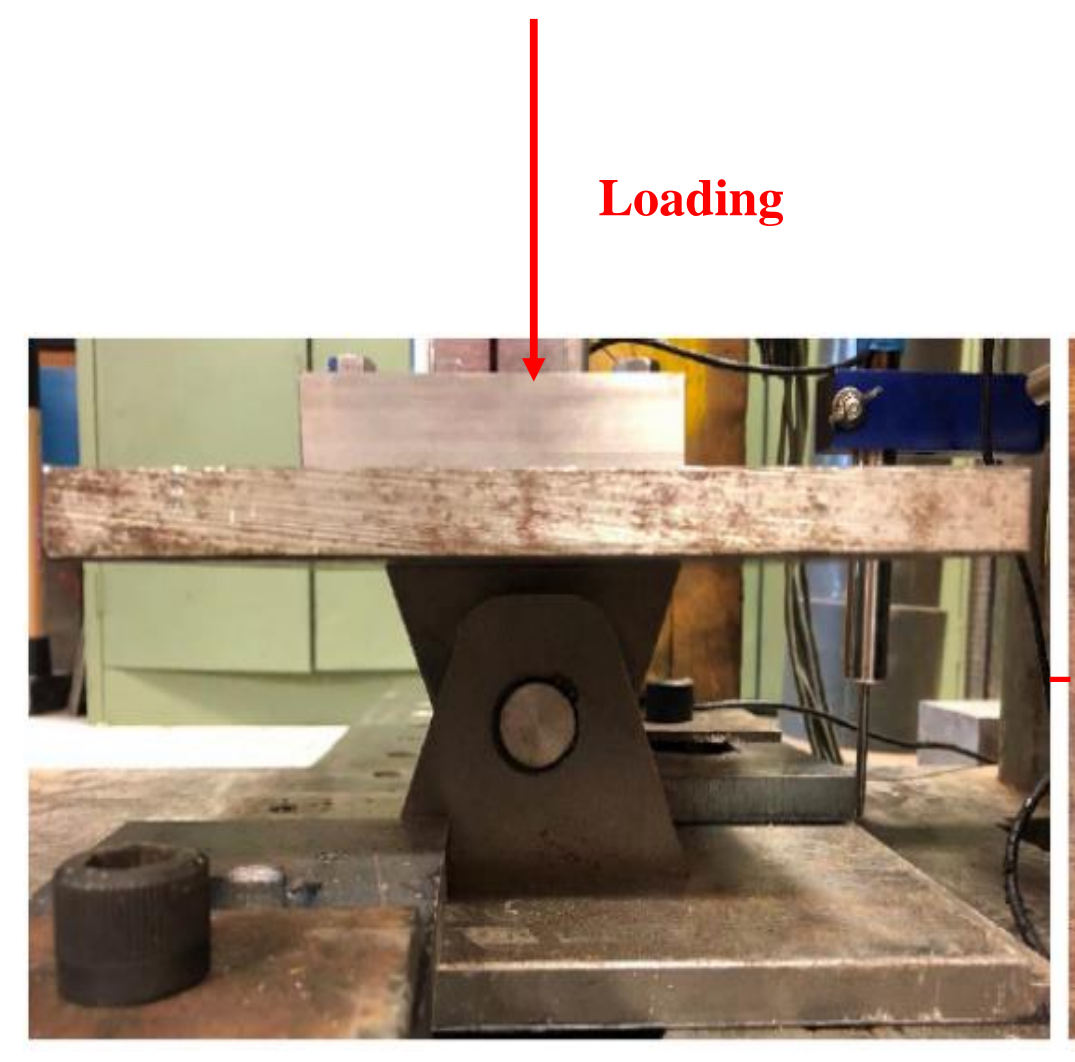

(a) Side view

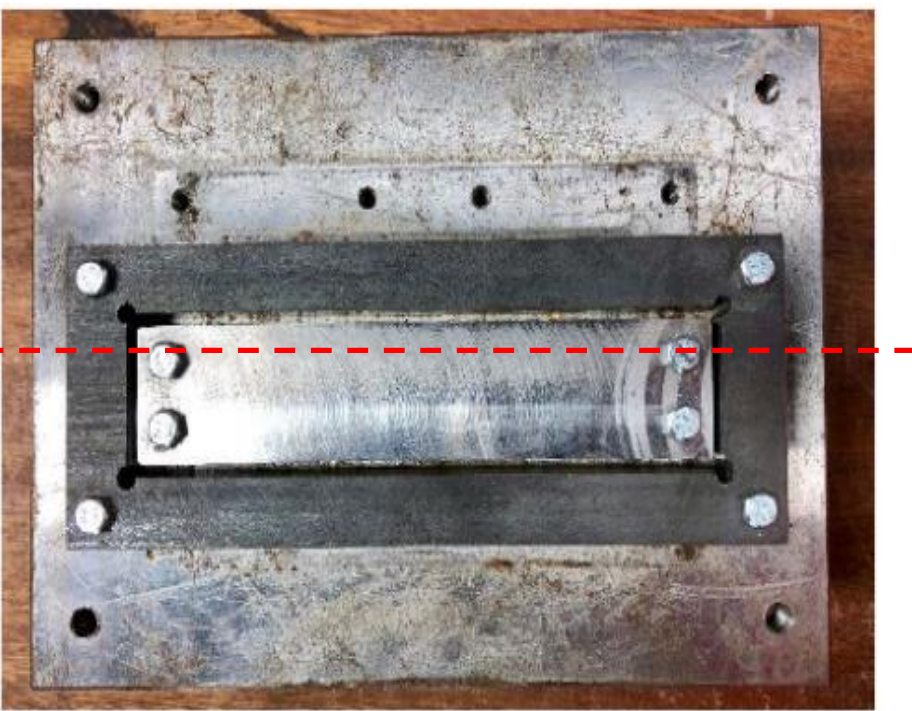

Center line of support

(b) Vertical view

Fig. 8 Photograph of the pin support

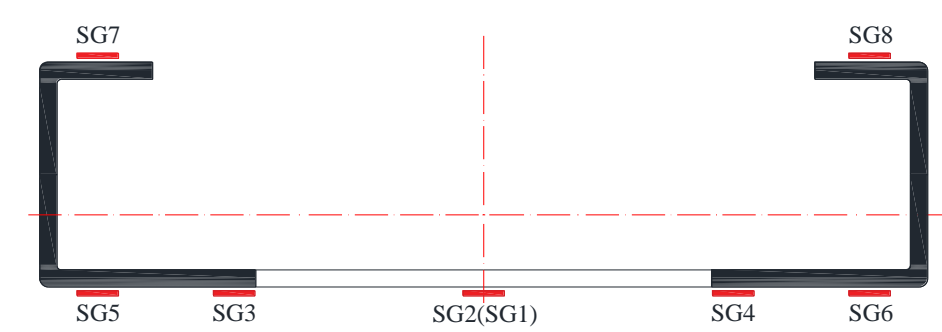

(a) Section with web openings

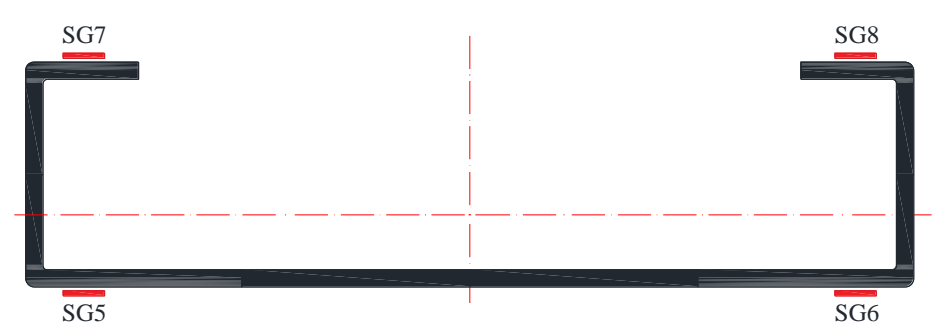

(b) Section without web openings

Fig. 9 Location of strain gauge at mid-height 


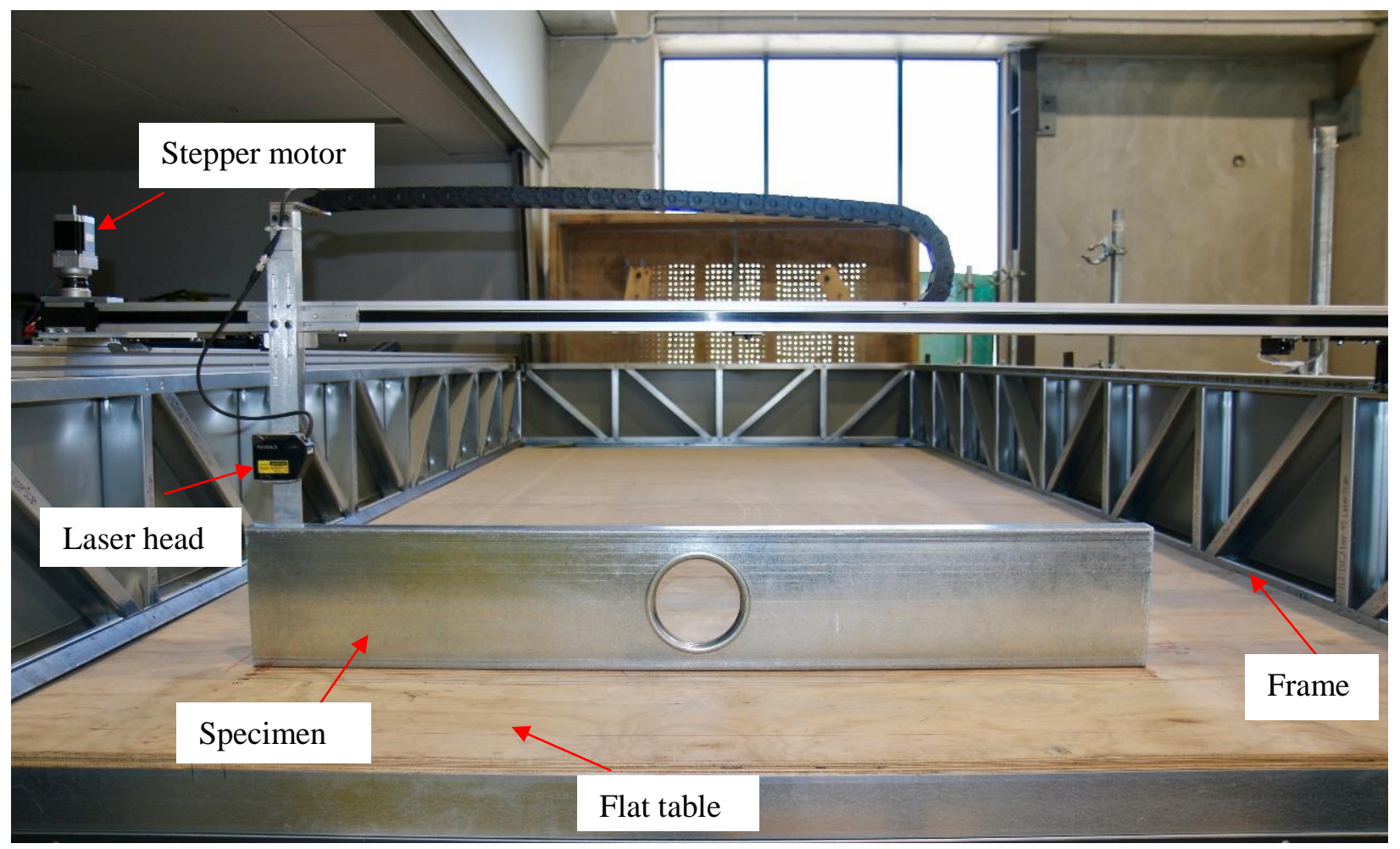

Fig. 10 Photograph of imperfection measurements setup 


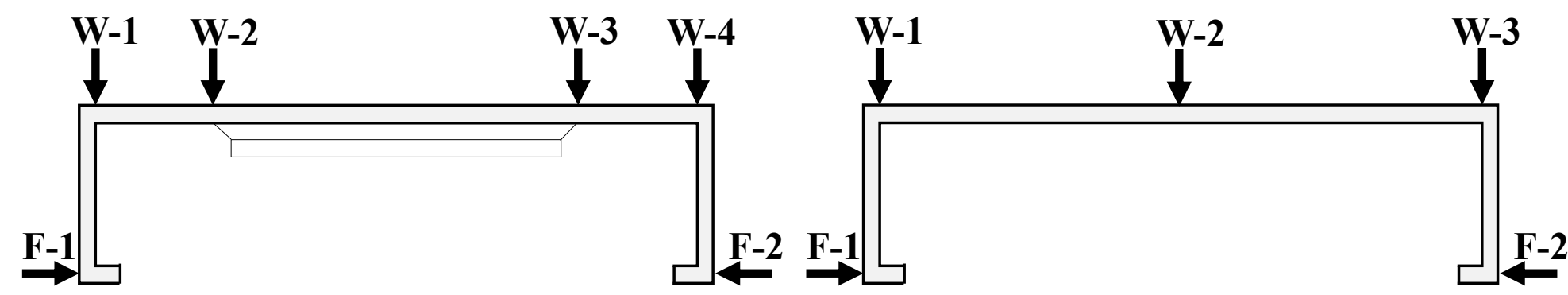

(a) Section with web openings

(b) Section without web openings

Fig. 11 Locations of the imperfection measurements 


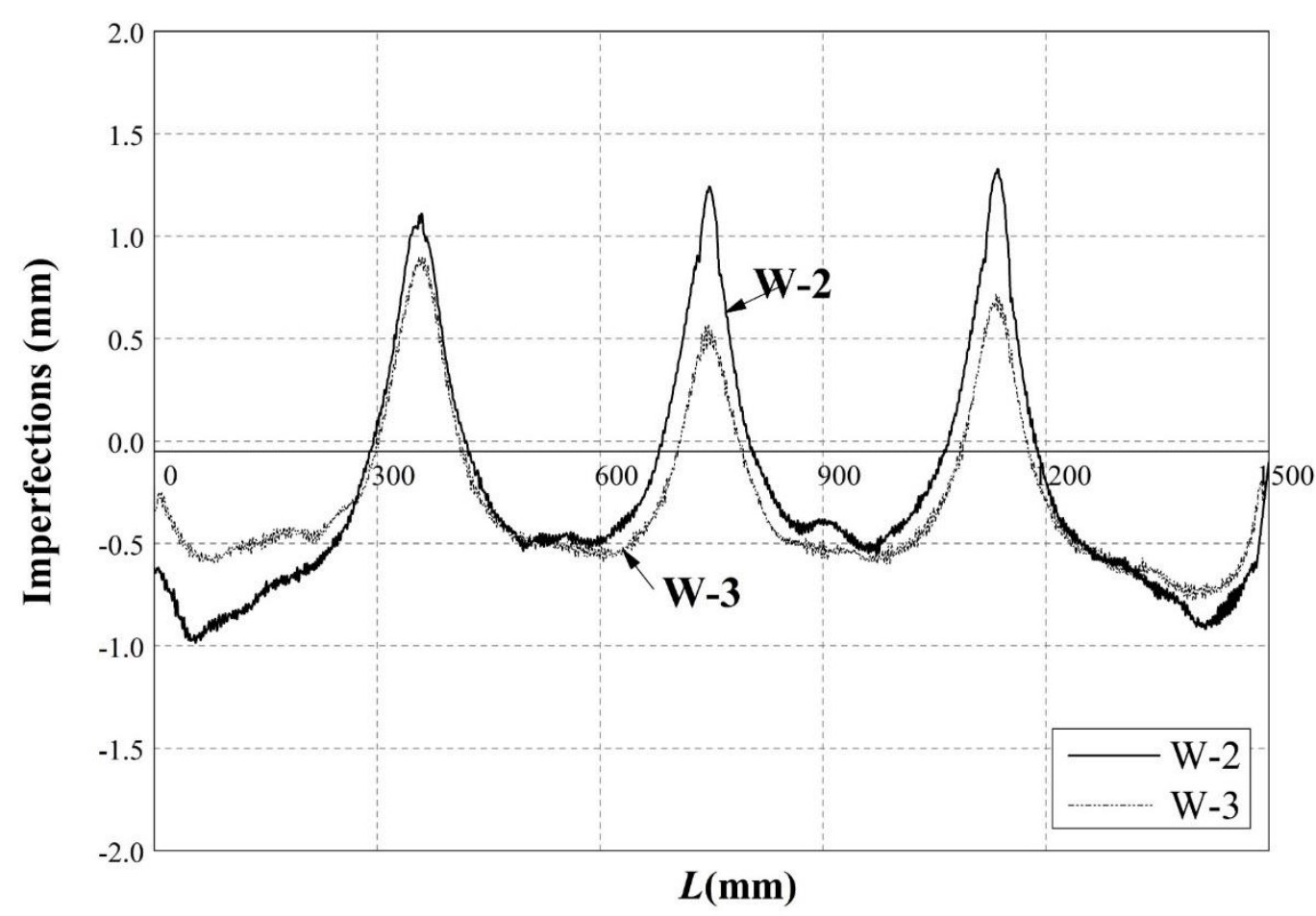

(a) Imperfection of W-2 and W-3

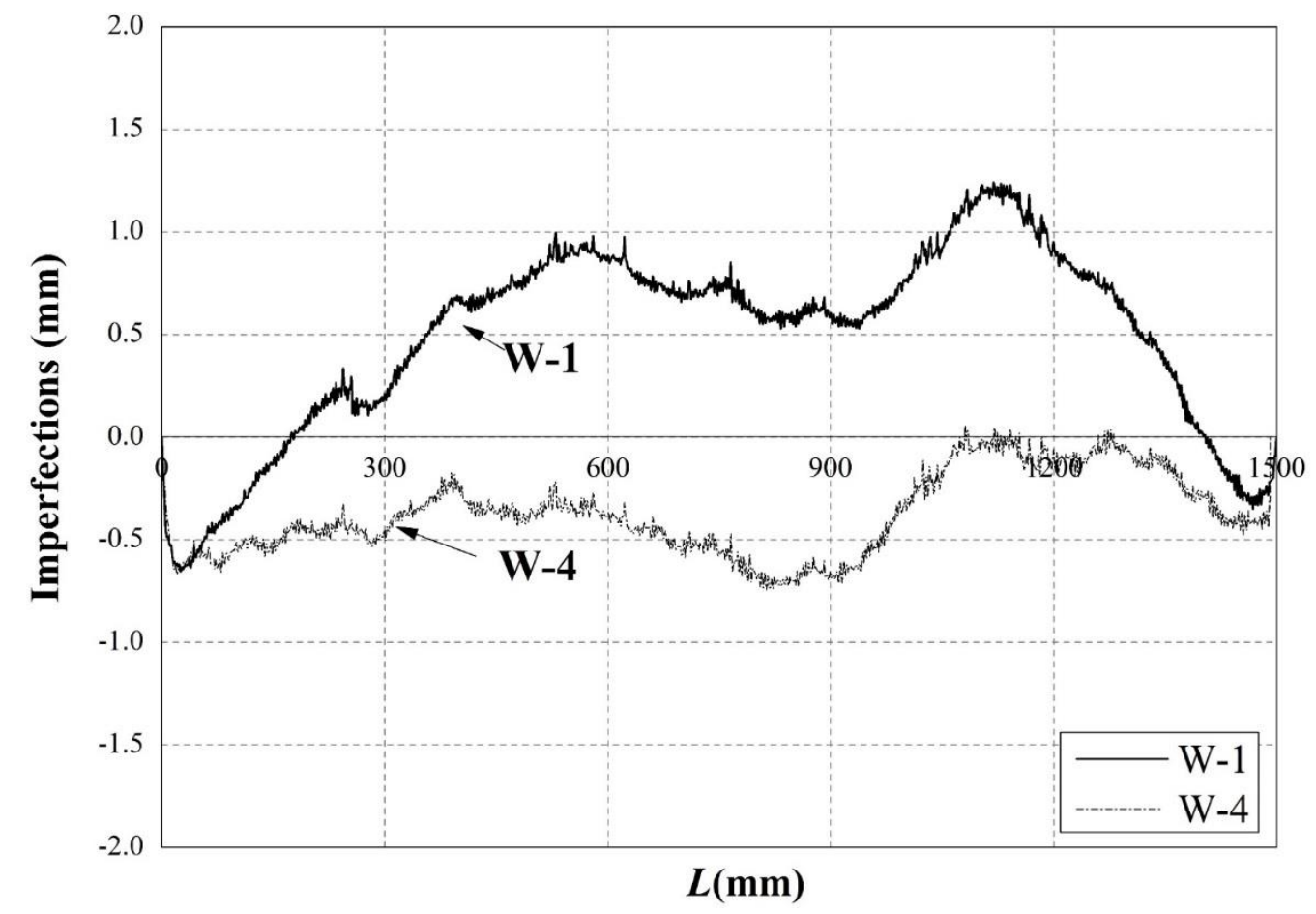

(b) Imperfection of W-1 and W-4

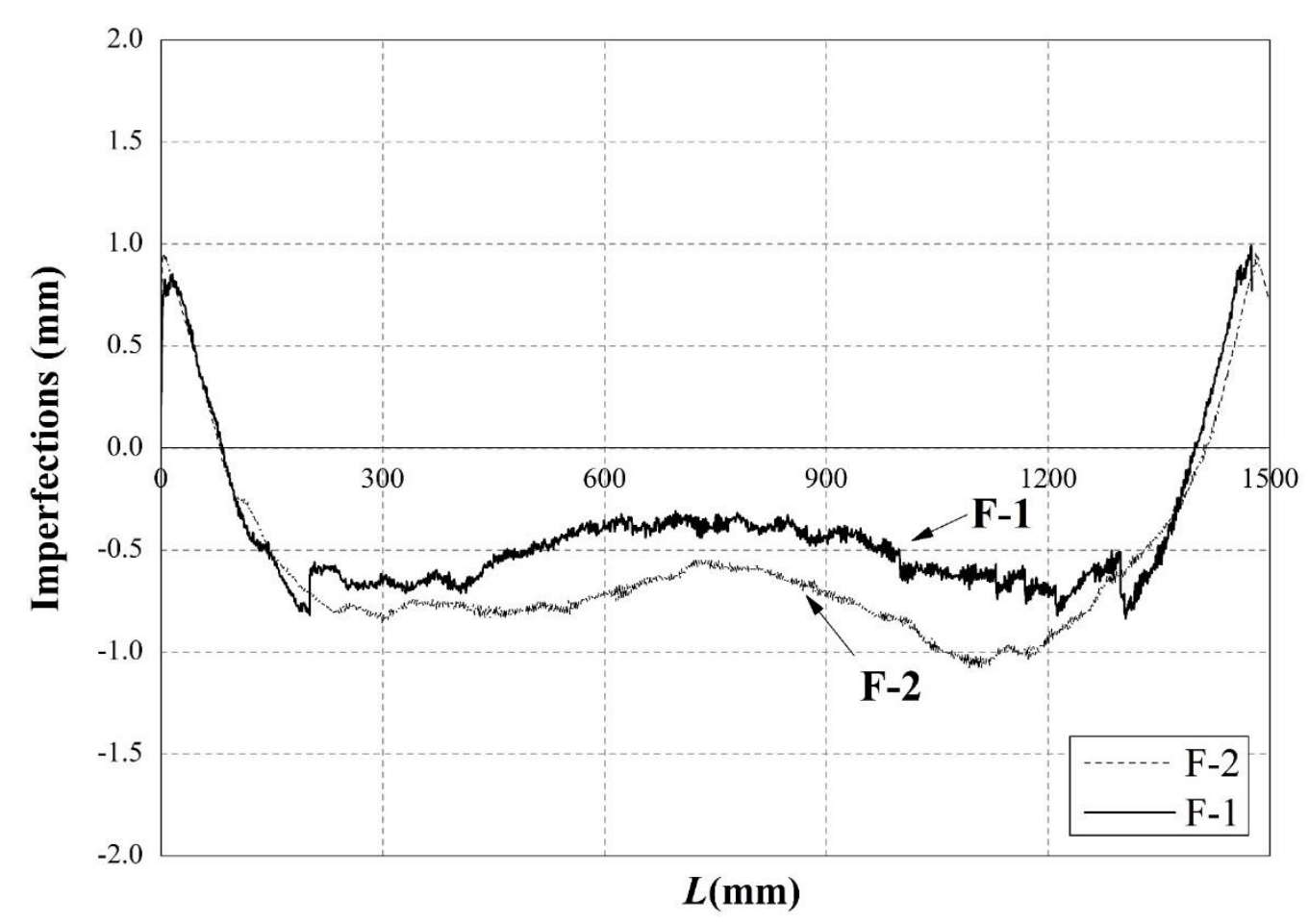

(c) Imperfection of F-1 and F-2

Fig. 12 Typical imperfection profile $(\mathrm{C} 190 \times 45 \times 15-\mathrm{L} 1500-\mathrm{EH} 3)$ 


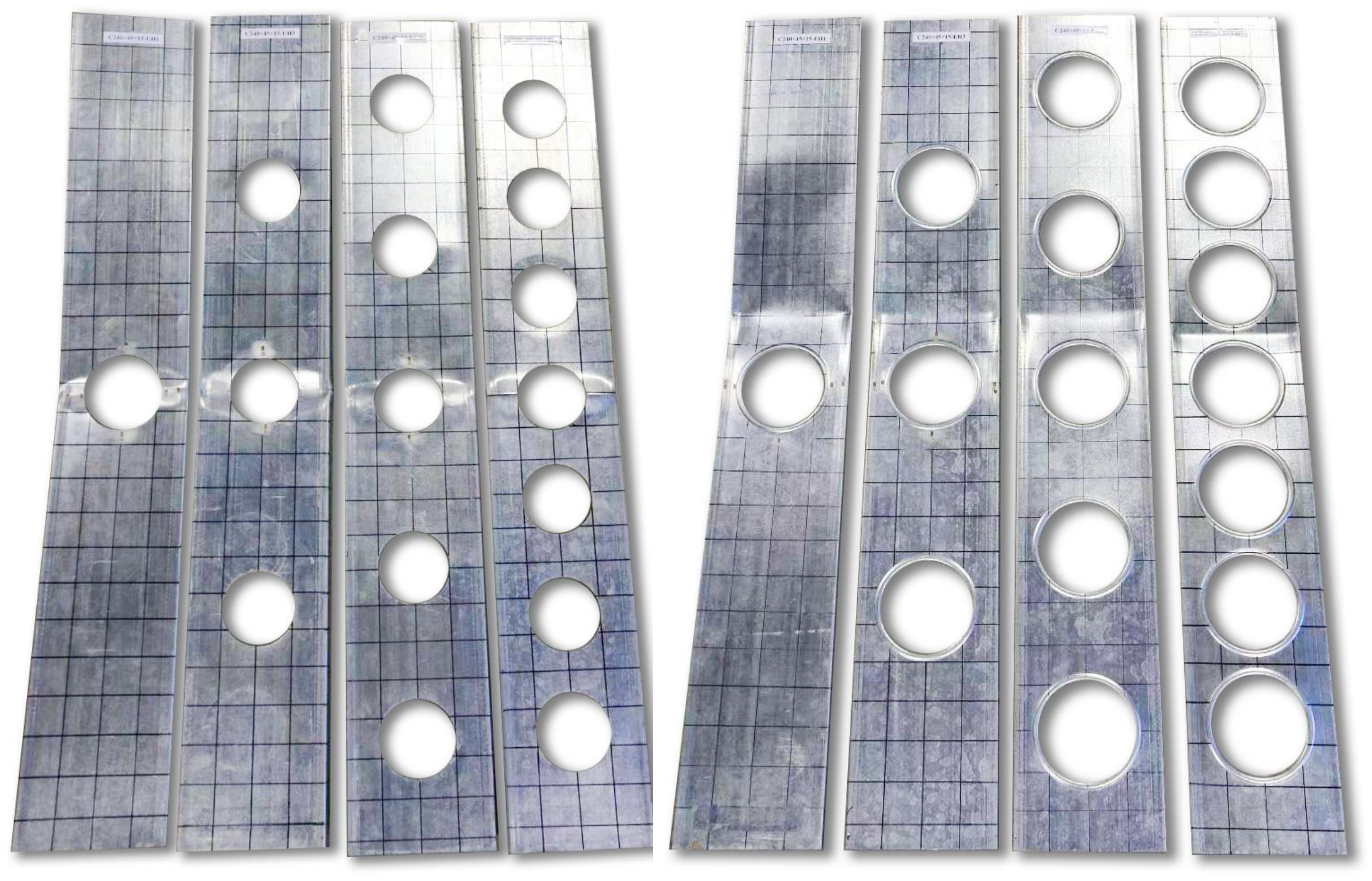

Fig. 13 Failure modes of $1500 \mathrm{~mm}$ long specimens with unstiffened and edge-stiffened web openings 


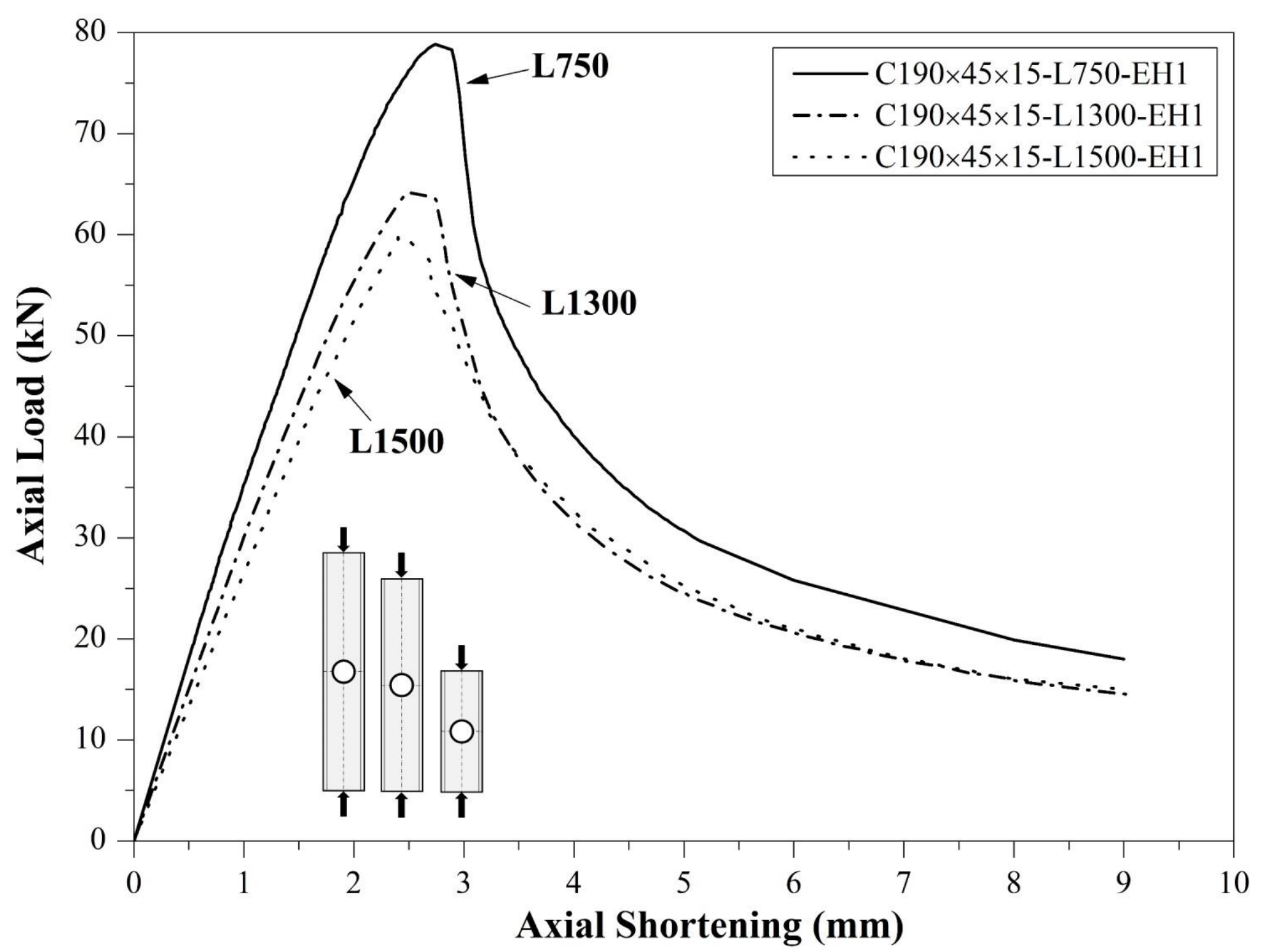

Fig. 14 Load versus axial shortening curves for specimens with various lengths 


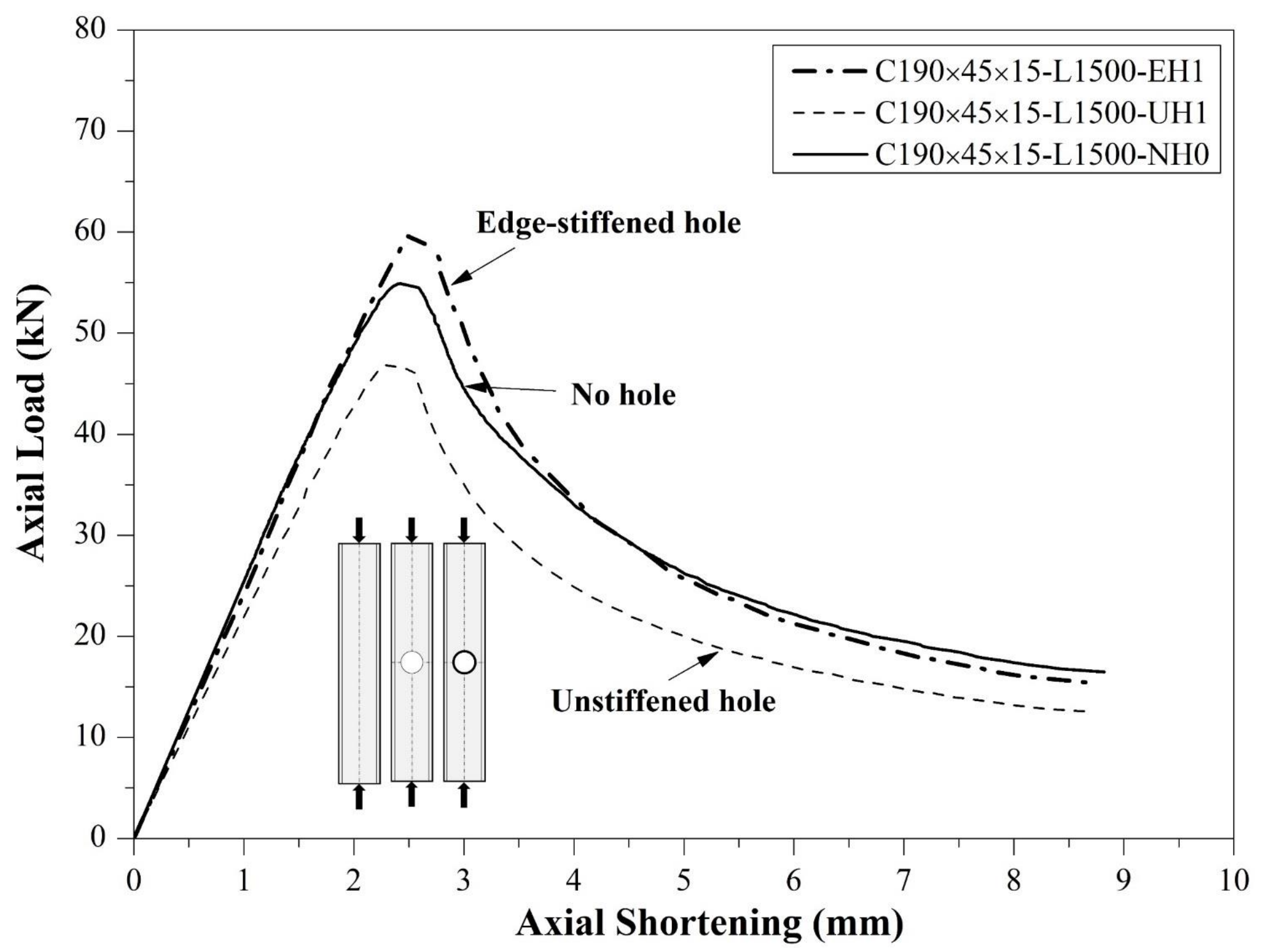

Fig. 15 Comparison of load-displacement response for specimens with and without web openings 


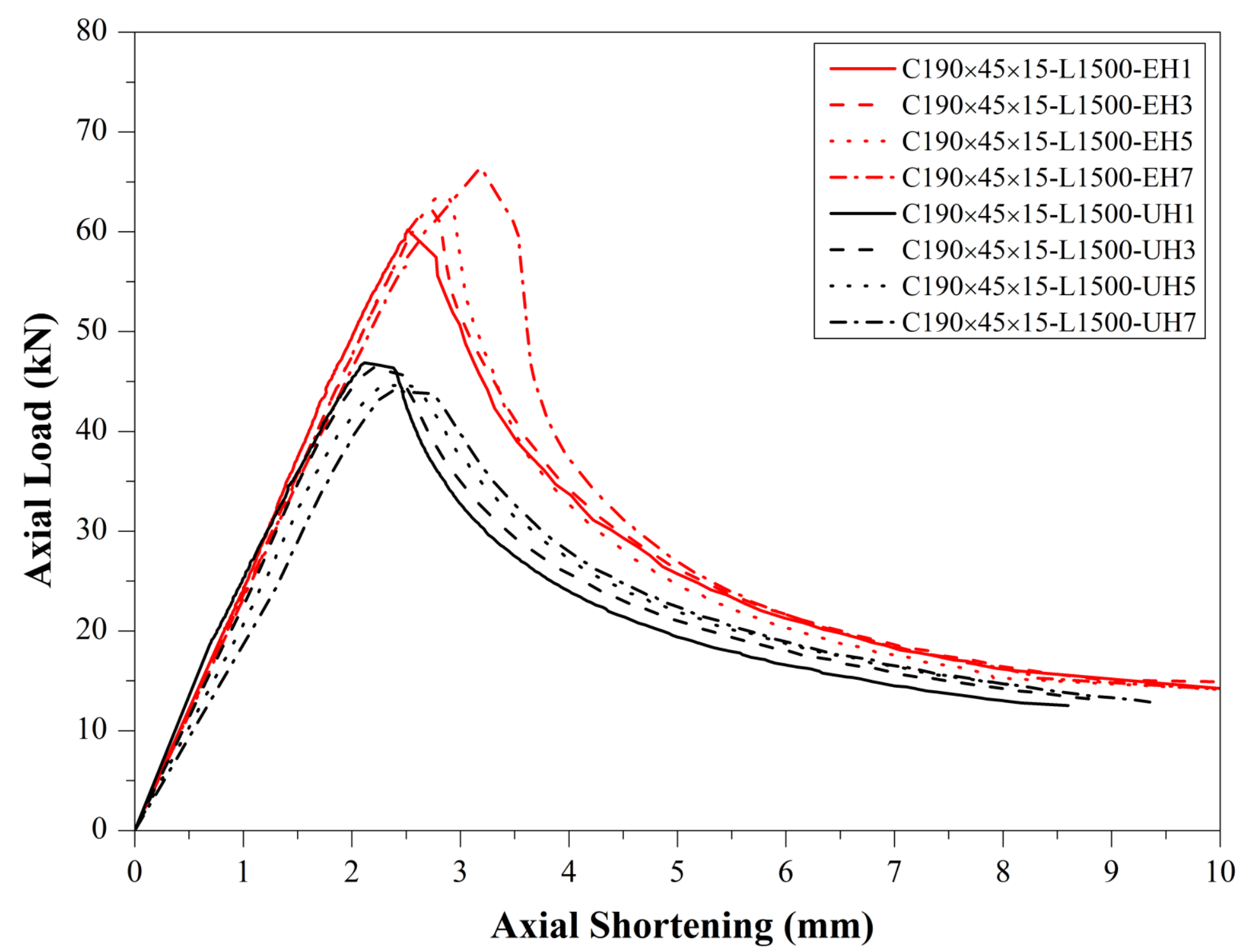

(a) Section $190 \times 45 \times 15$

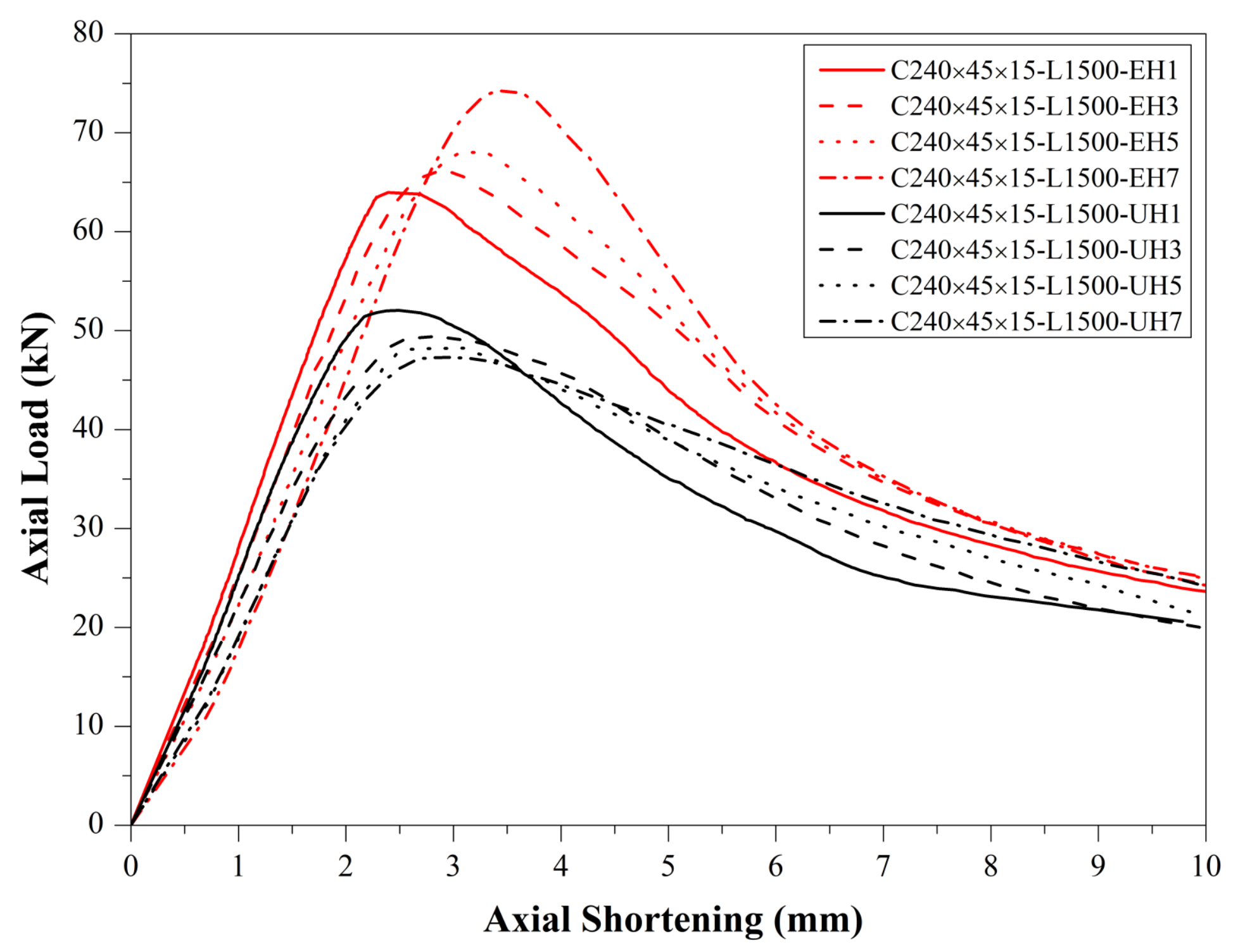

(b) Section $240 \times 45 \times 15$

Fig. 16 Axial load versus axial shortening curves of specimens with different opening spacing 


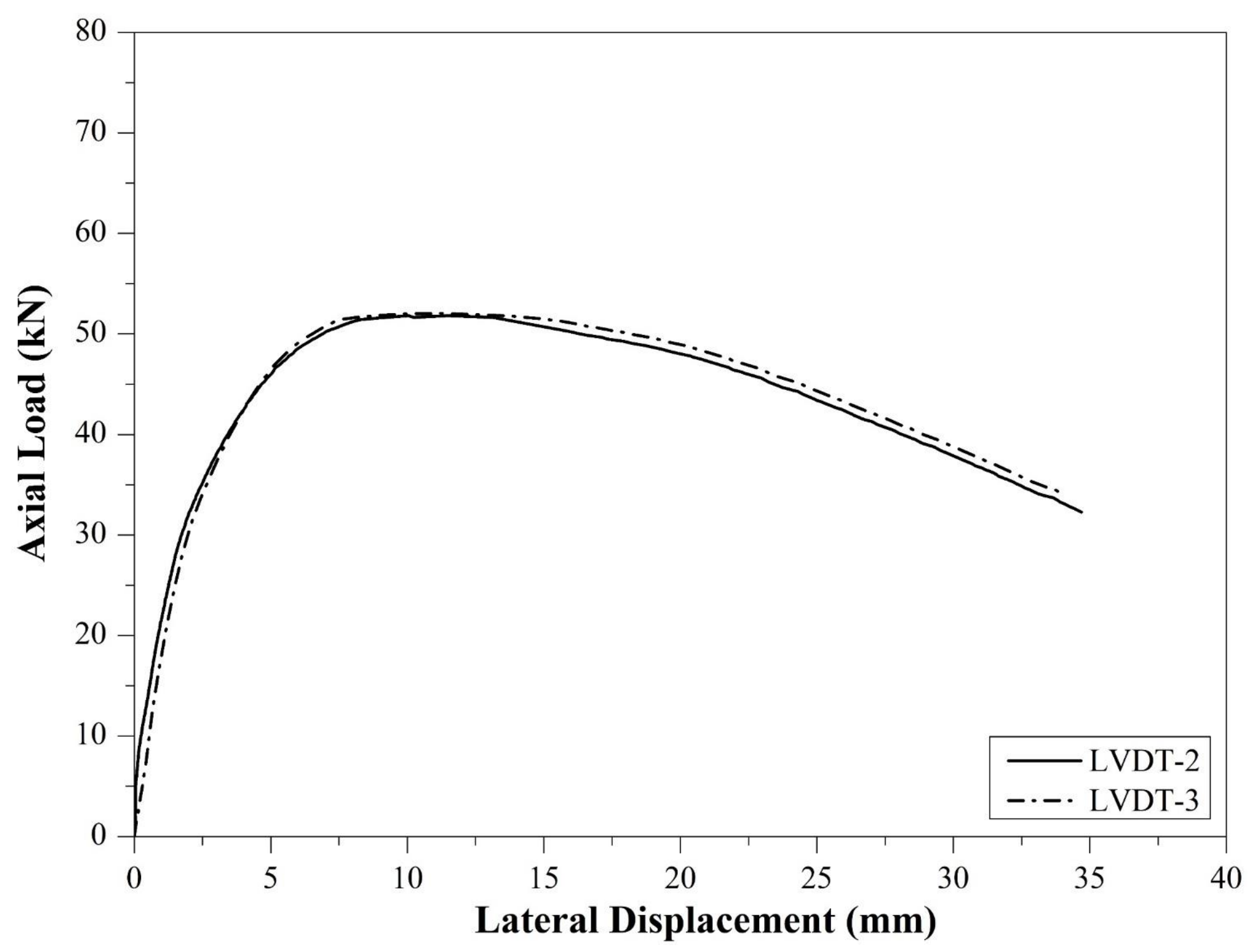

(a) $\mathrm{C} 240 \times 45 \times 15-\mathrm{L} 1500-\mathrm{UH} 1$

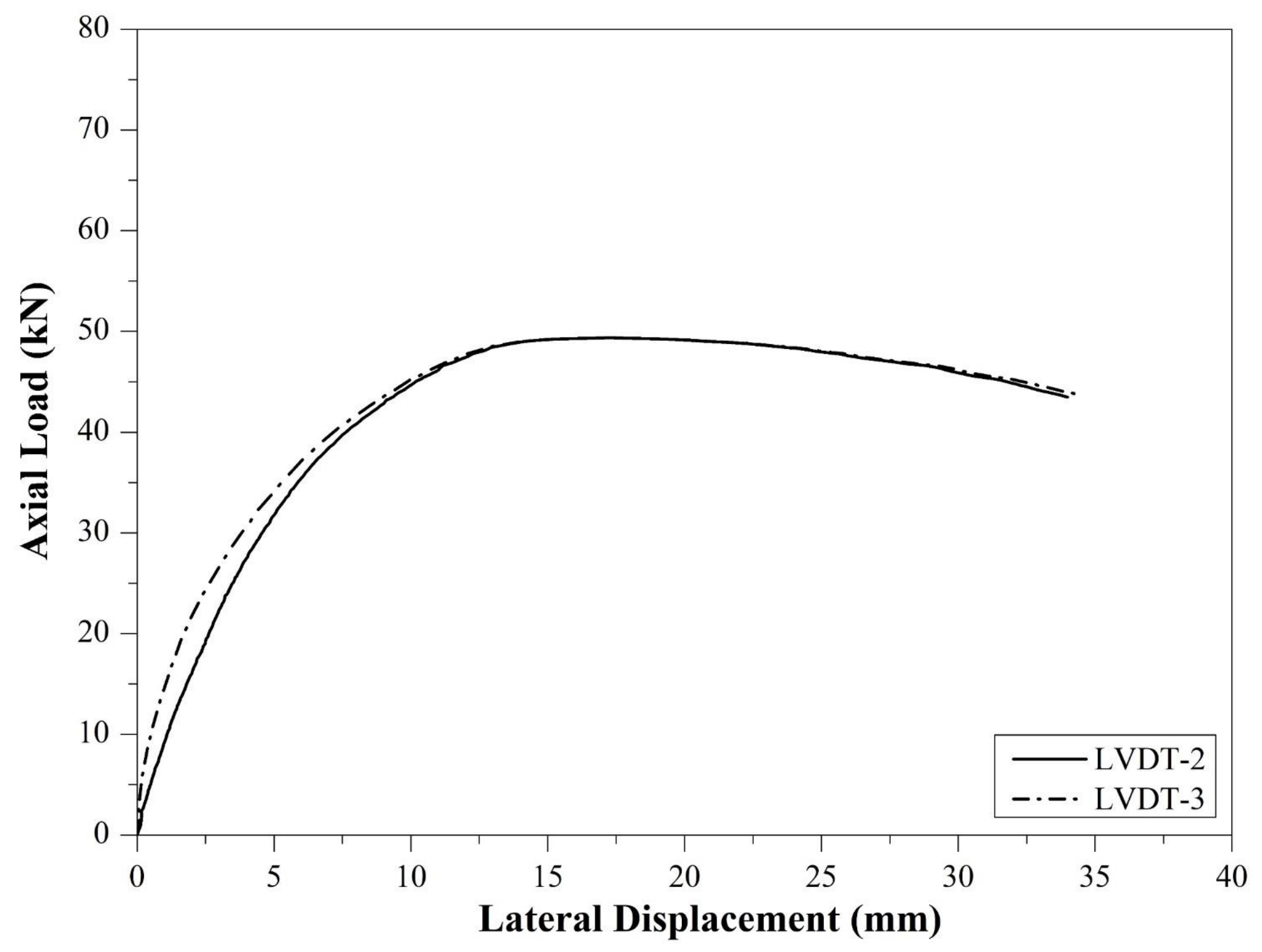

(b) $\mathrm{C} 240 \times 45 \times 15-\mathrm{L} 1500-\mathrm{UH} 3$ 


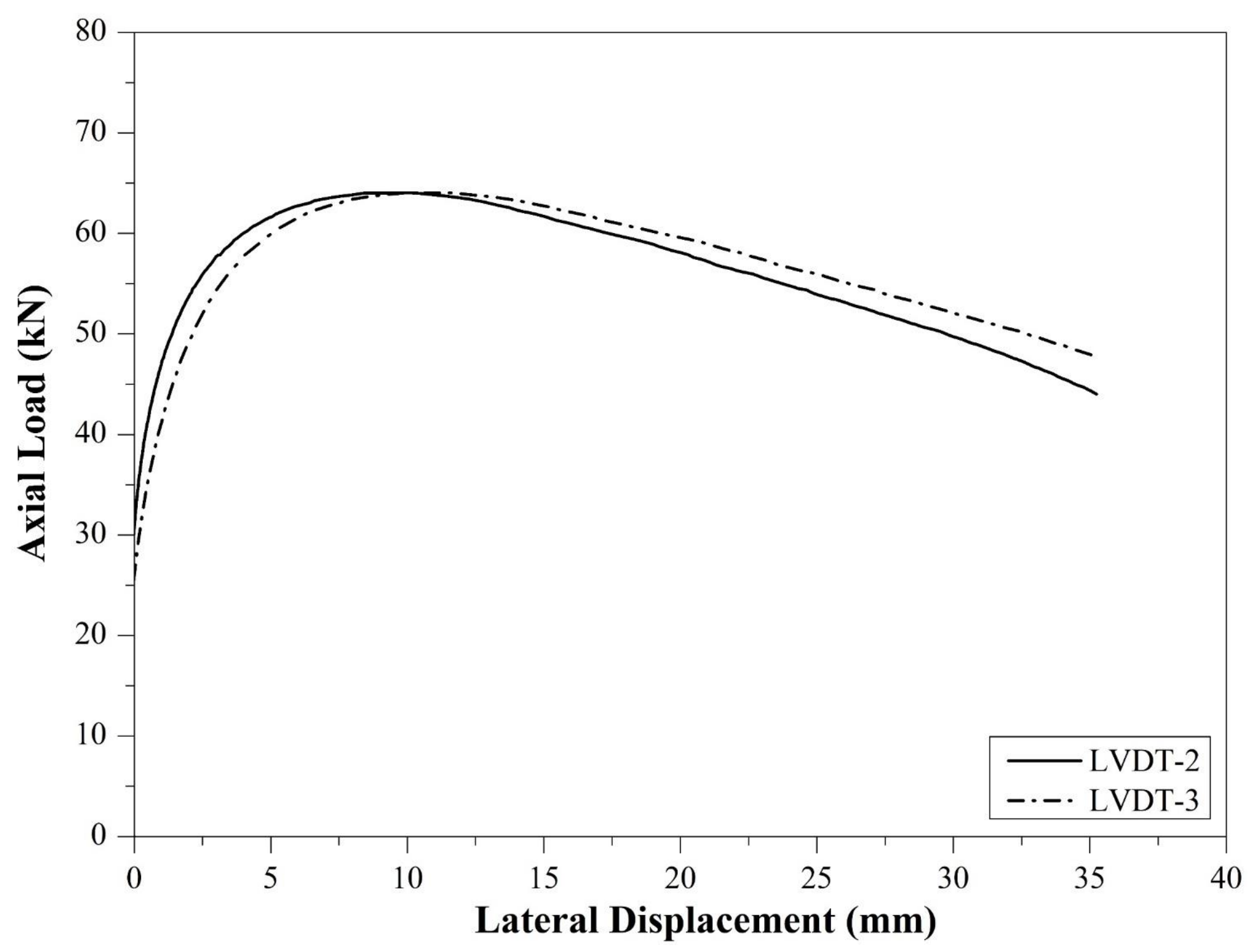

(c) $\mathrm{C} 240 \times 45 \times 15-\mathrm{L} 1500-\mathrm{EH} 1$

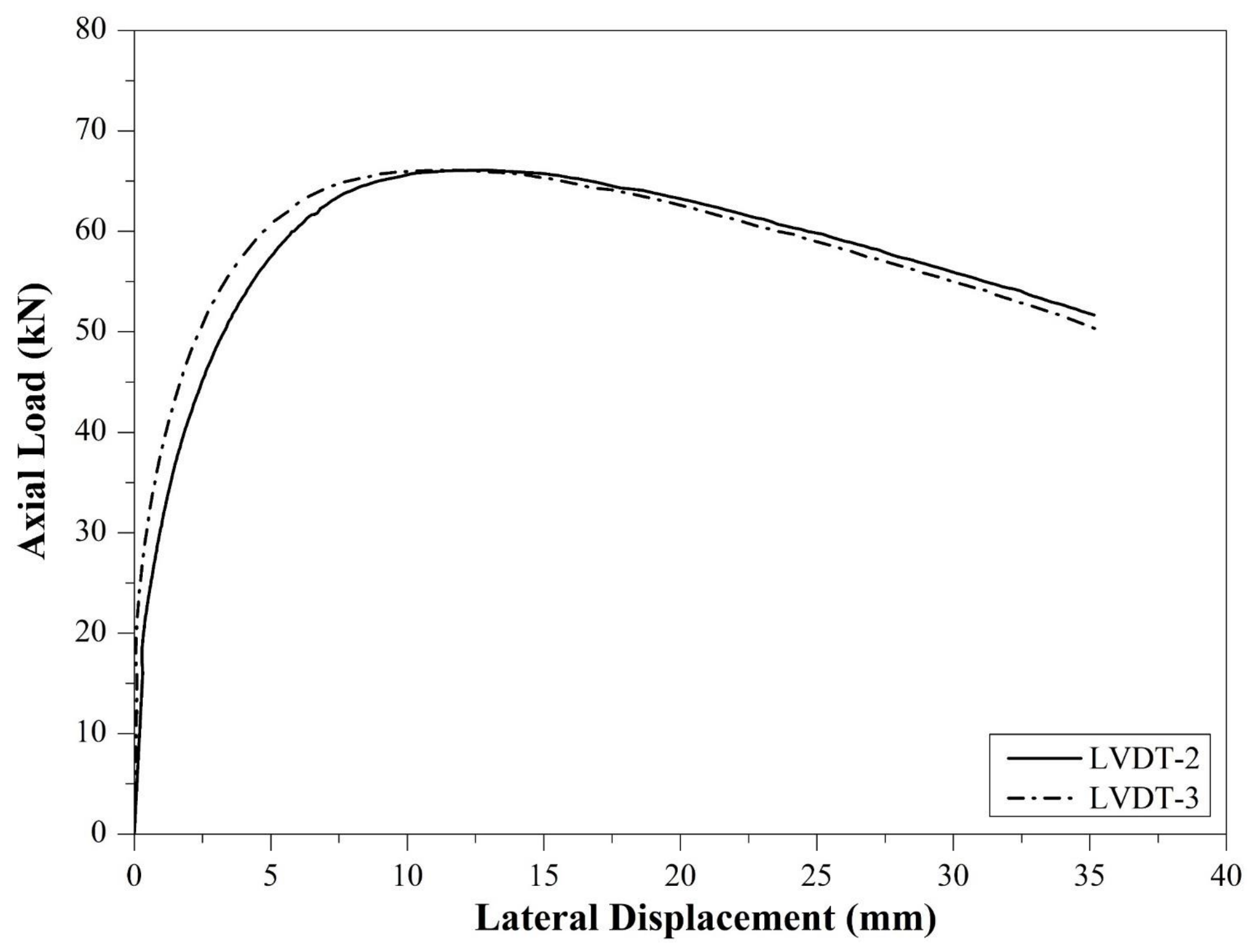

(d) $\mathrm{C} 240 \times 45 \times 15-\mathrm{L} 1500-\mathrm{EH} 3$

Fig. 17 Axial load versus lateral displacement relationship at mid-height of specimens 


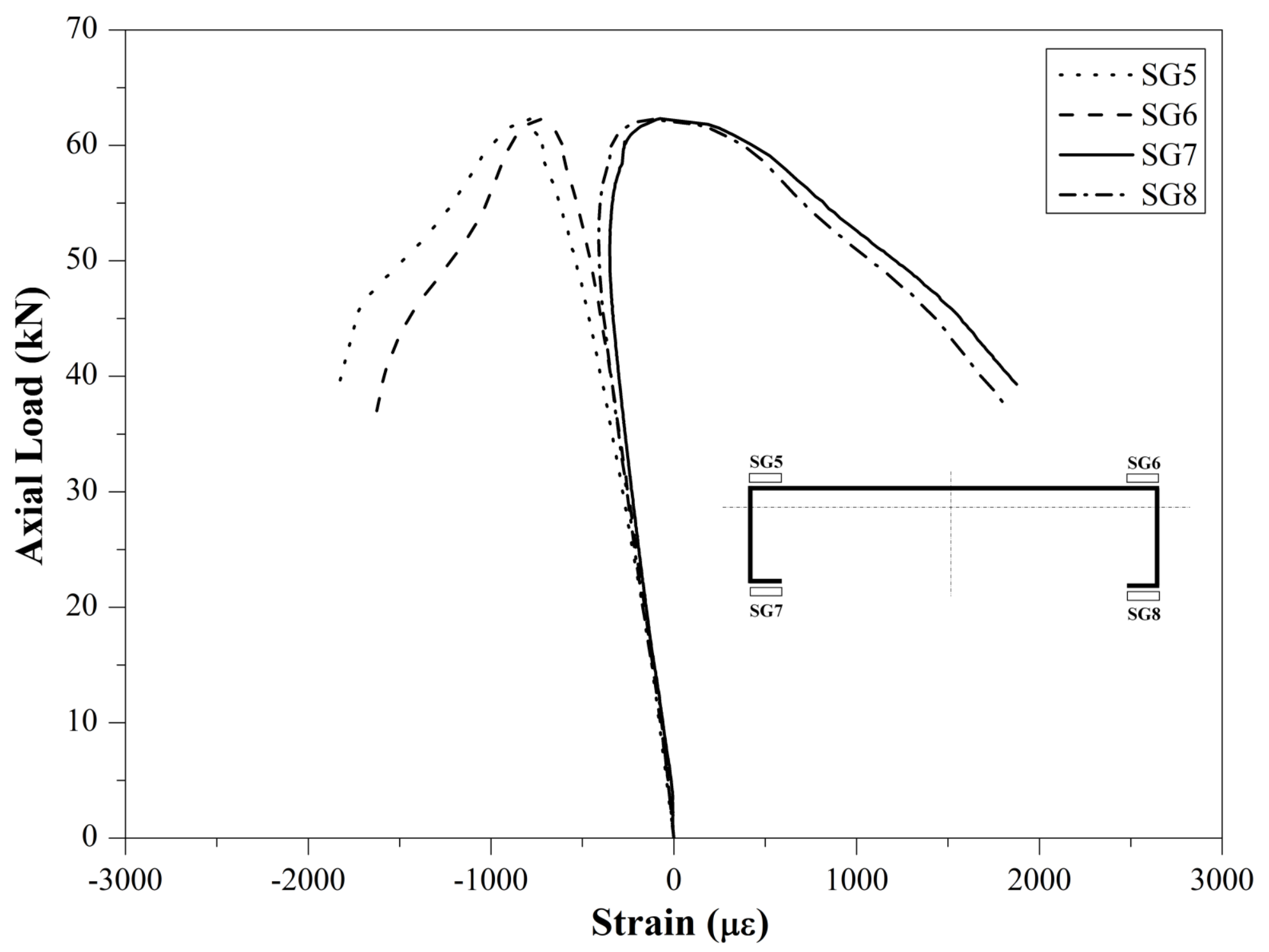

(a) C190×45×15-L1500-EH3

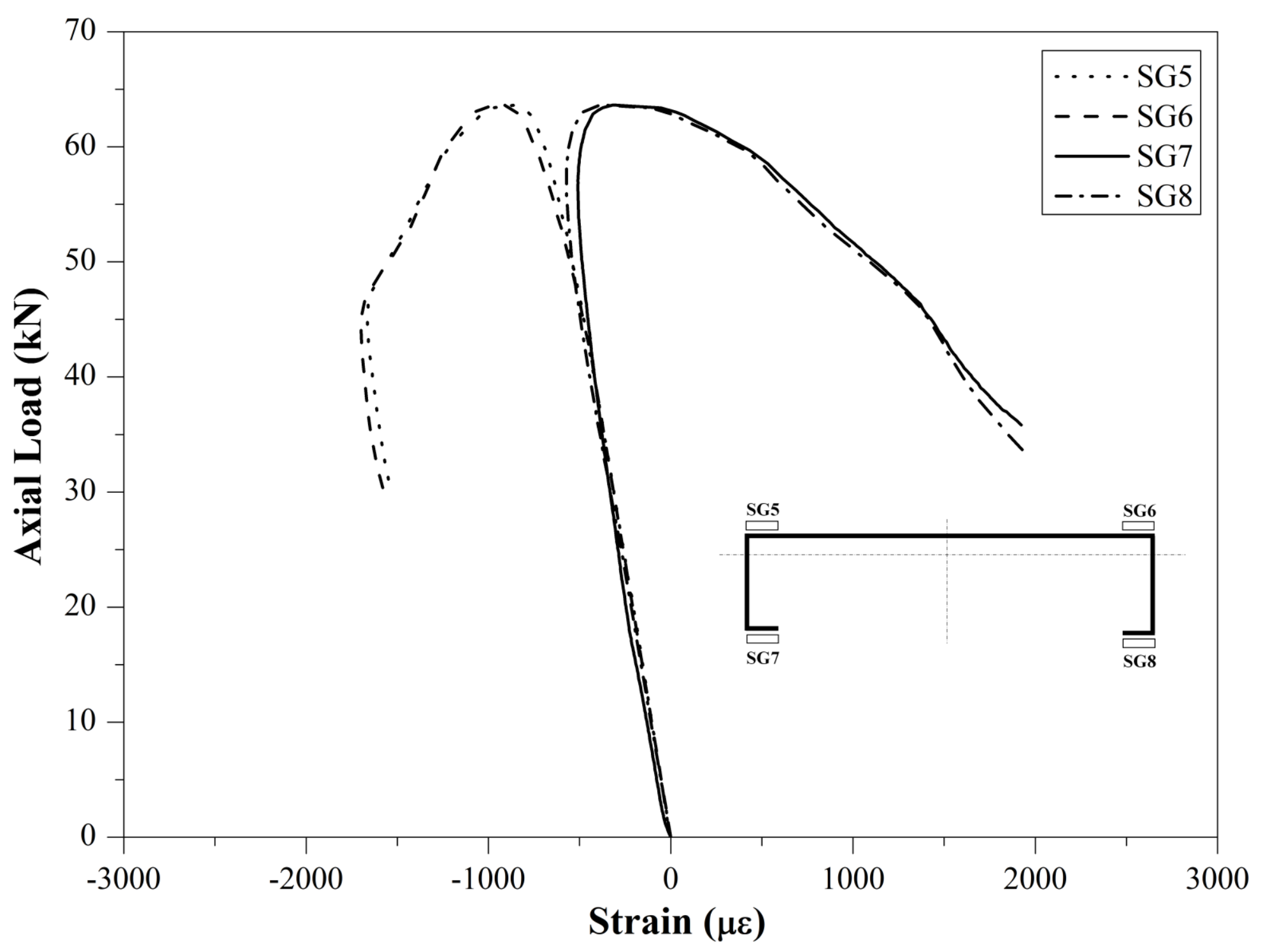

(b) $\mathrm{C} 190 \times 45 \times 15-\mathrm{L} 1500-\mathrm{EH} 5$

Fig. 18 Axial load versus strain 


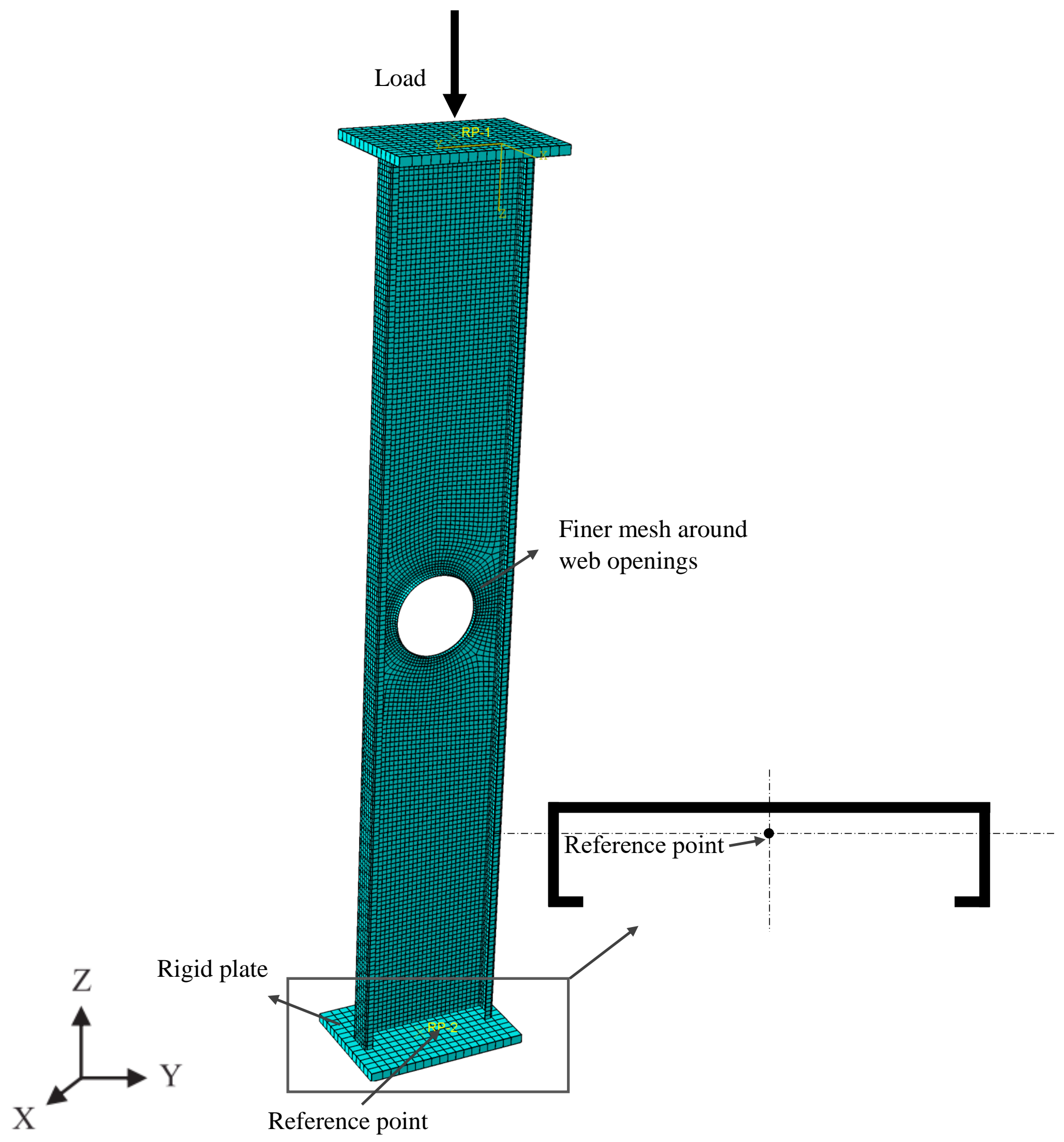

Fig. 19 Boundary condition and mesh type for C240×45×15-L1500-EH1 


$$
11
$$




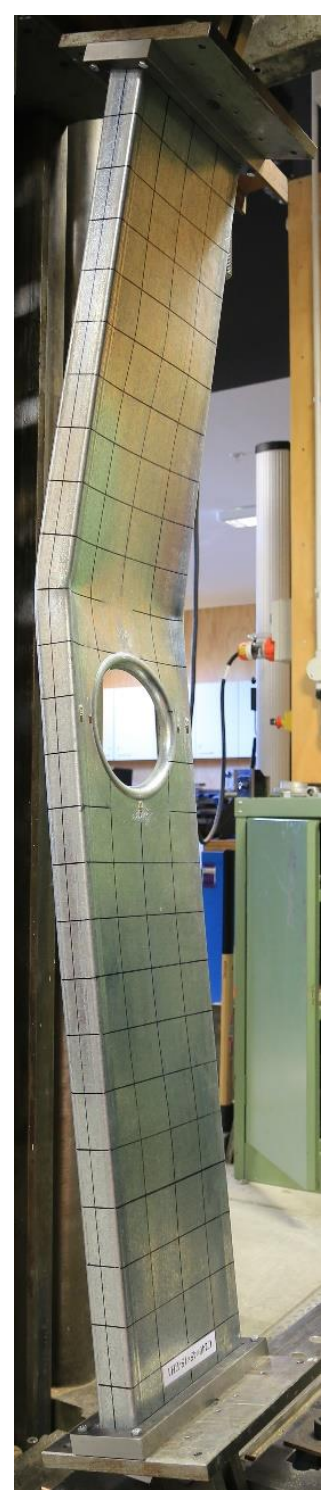

(i) Test

(a) $\mathrm{C} 240 \times 45 \times 15-\mathrm{L} 1500-\mathrm{EH} 1$

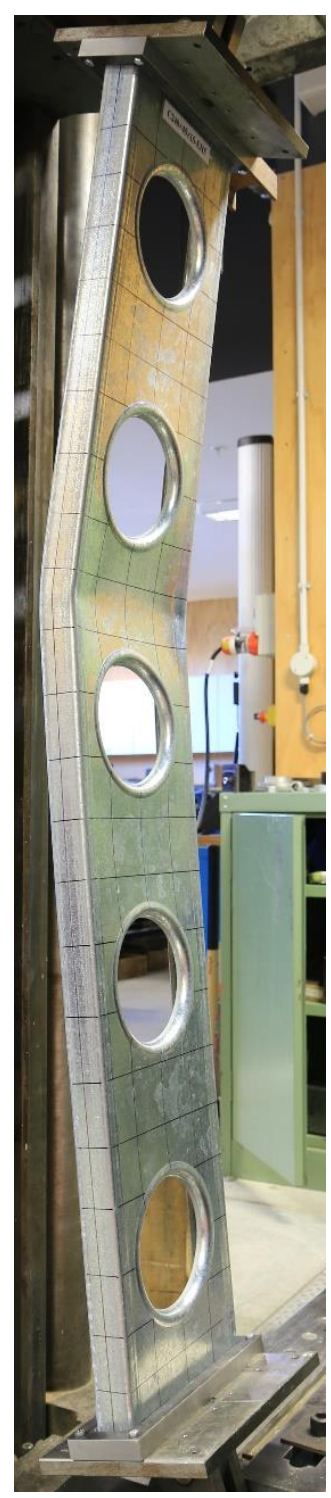

(i) Test

(c) $\mathrm{C} 240 \times 45 \times 15-\mathrm{L} 1500-\mathrm{EH} 5$
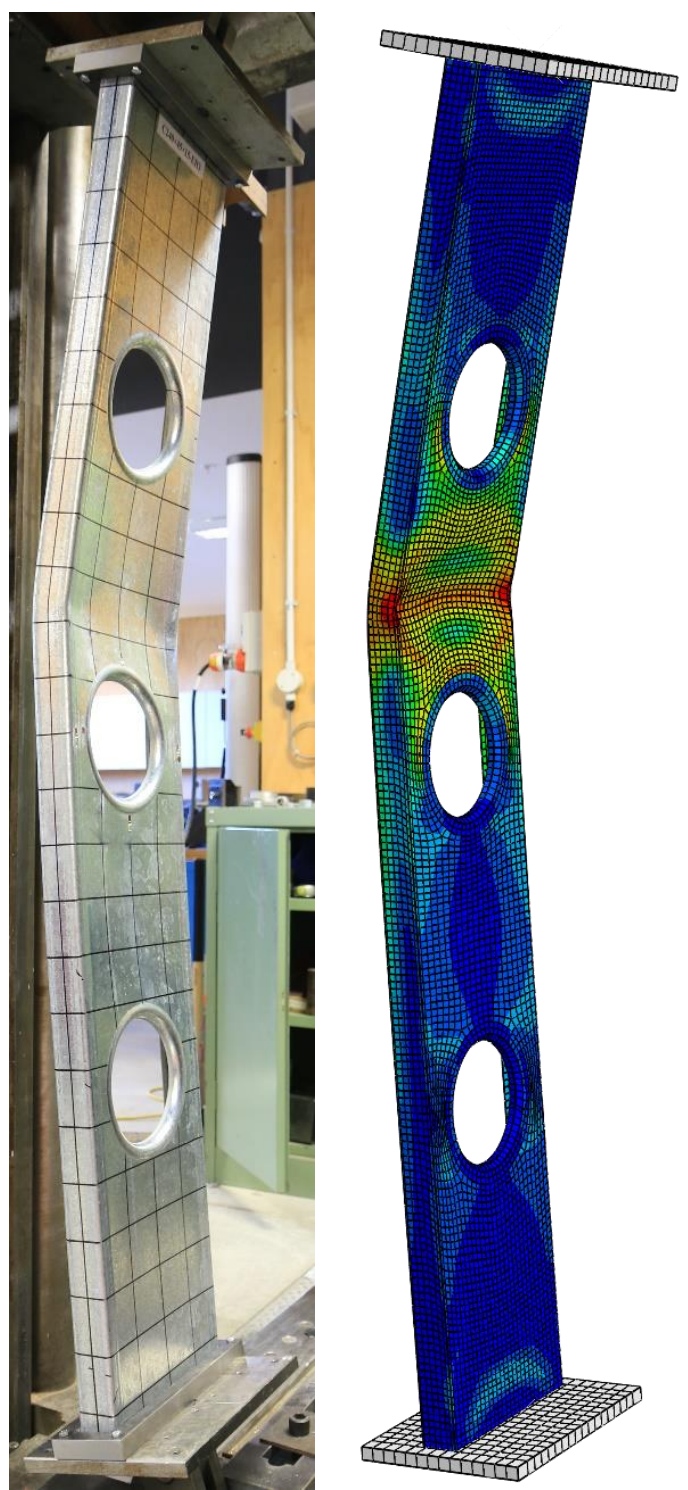

(i) Test

(ii) FEA

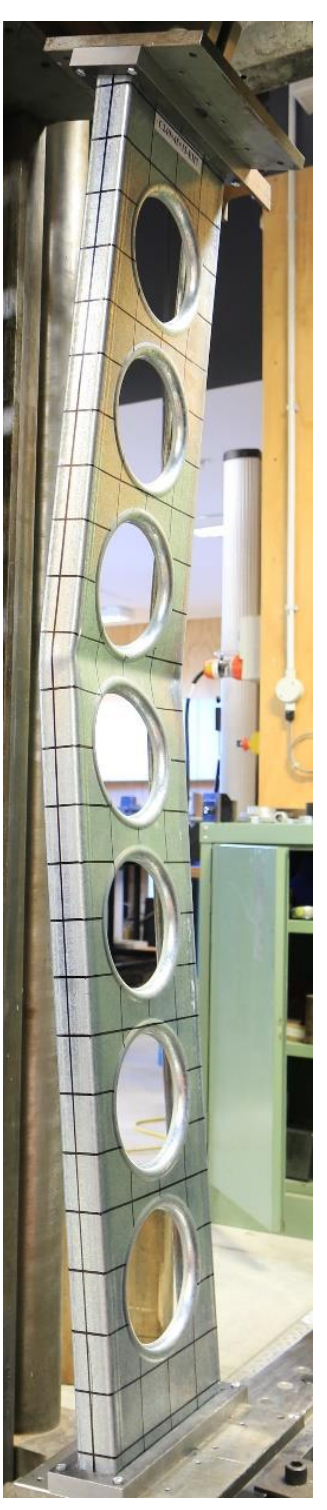

(i) Test

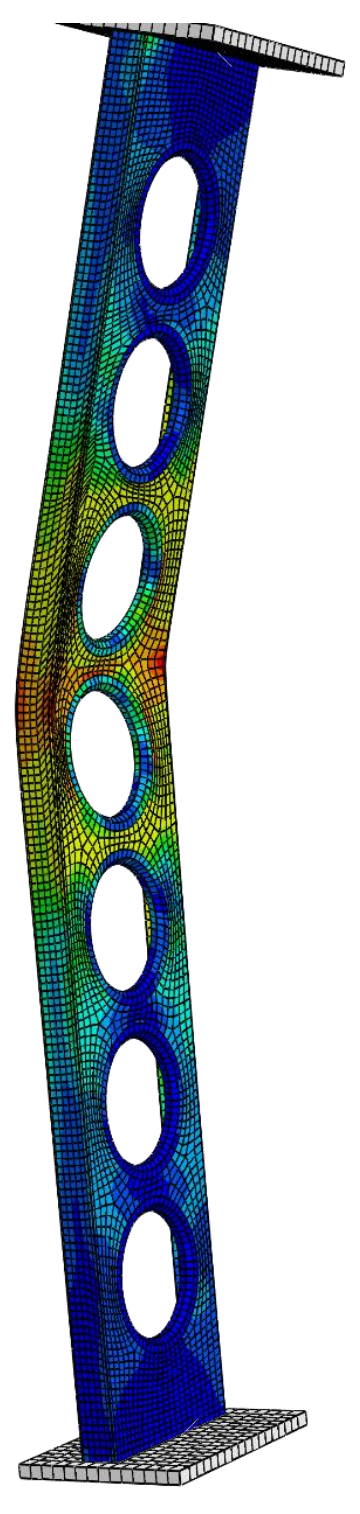

(ii) FEA

(d) $\mathrm{C} 240 \times 45 \times 15-\mathrm{L} 1500-\mathrm{EH} 7$

Fig. 21 Deformed shapes at failure from experiments and FEA 


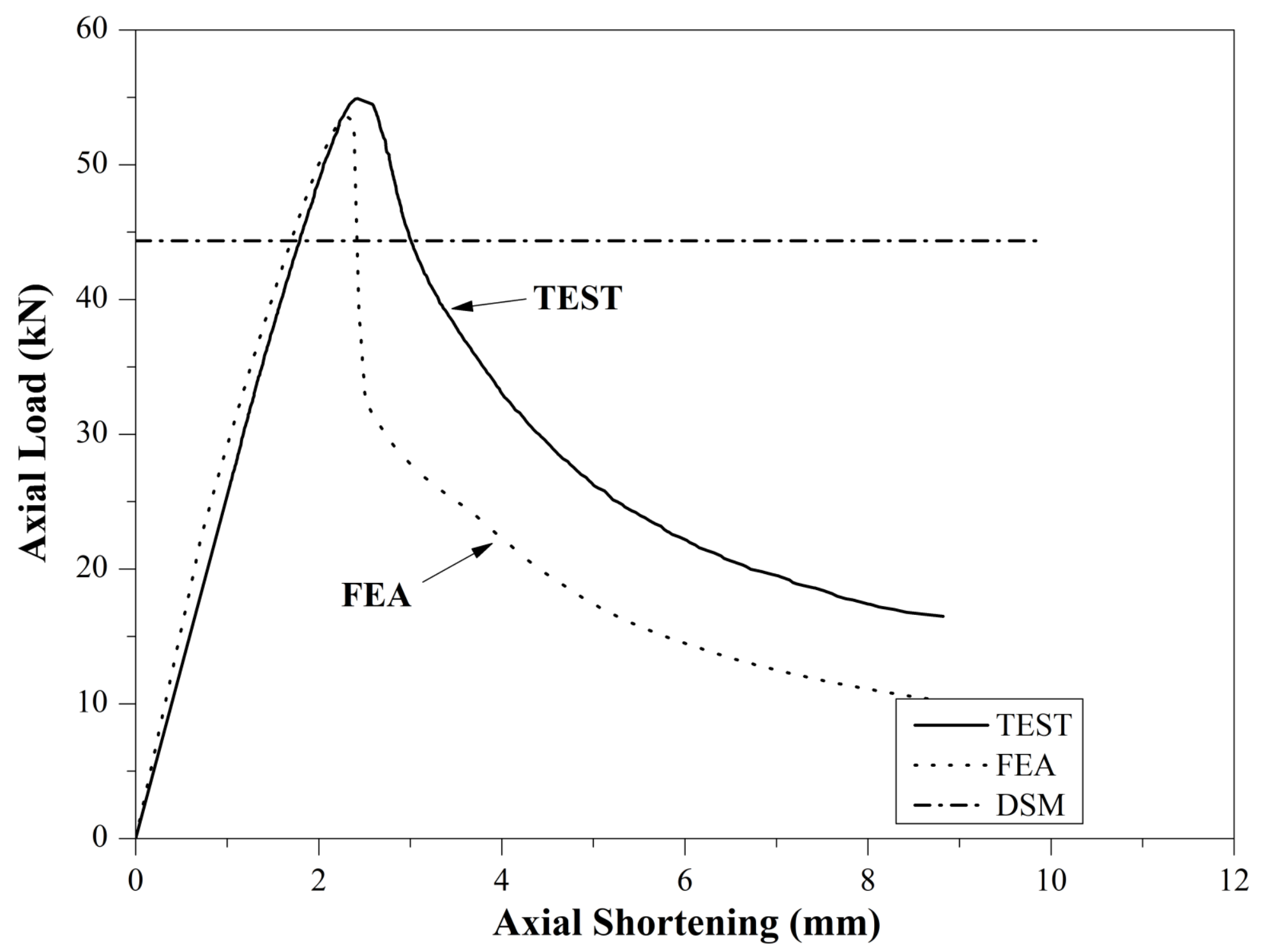

(a) $\mathrm{C} 190 \times 45 \times 15-\mathrm{L} 1500-\mathrm{NH} 0$

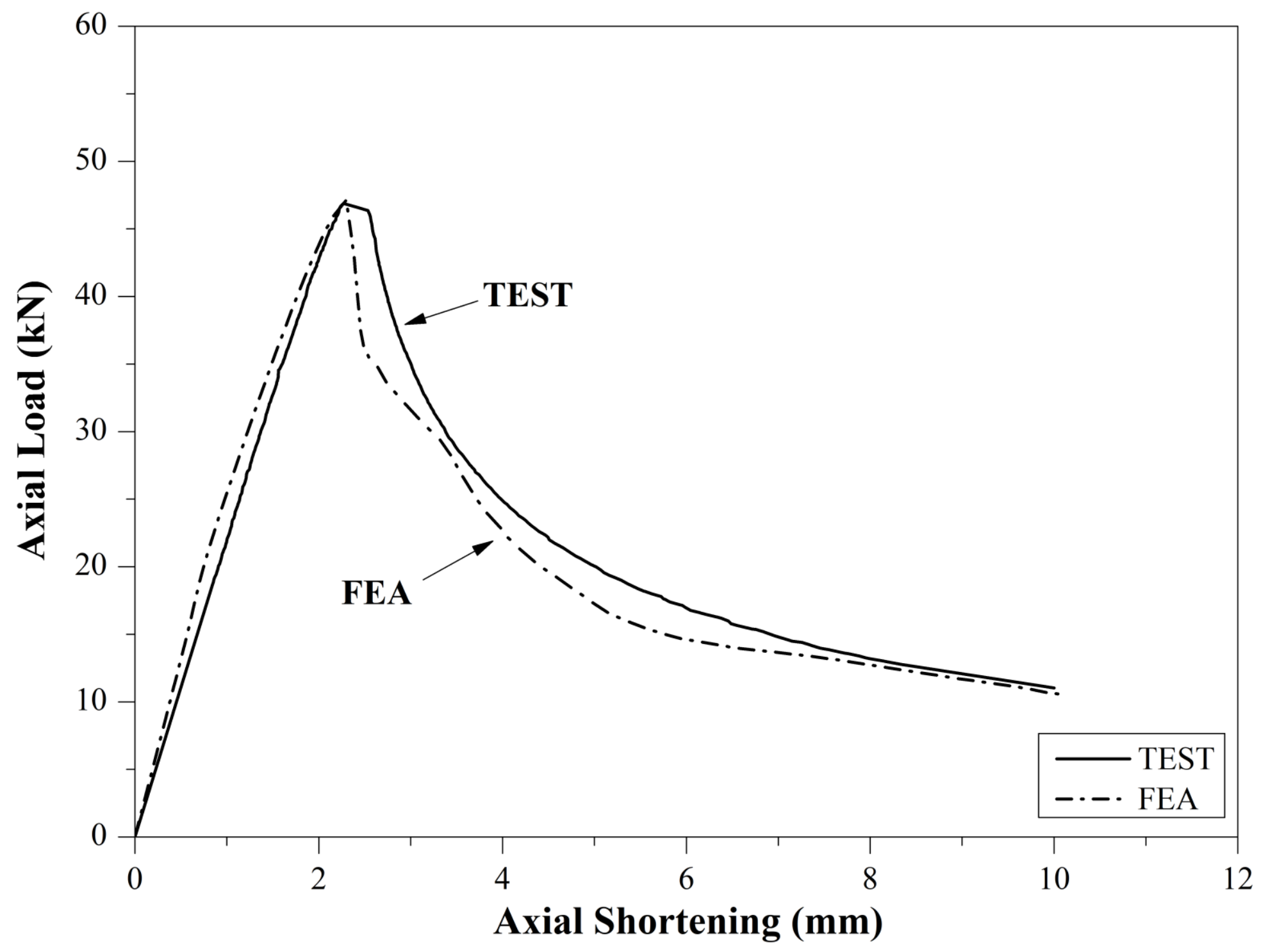

(b) C190×45×15-L1500-UH1 


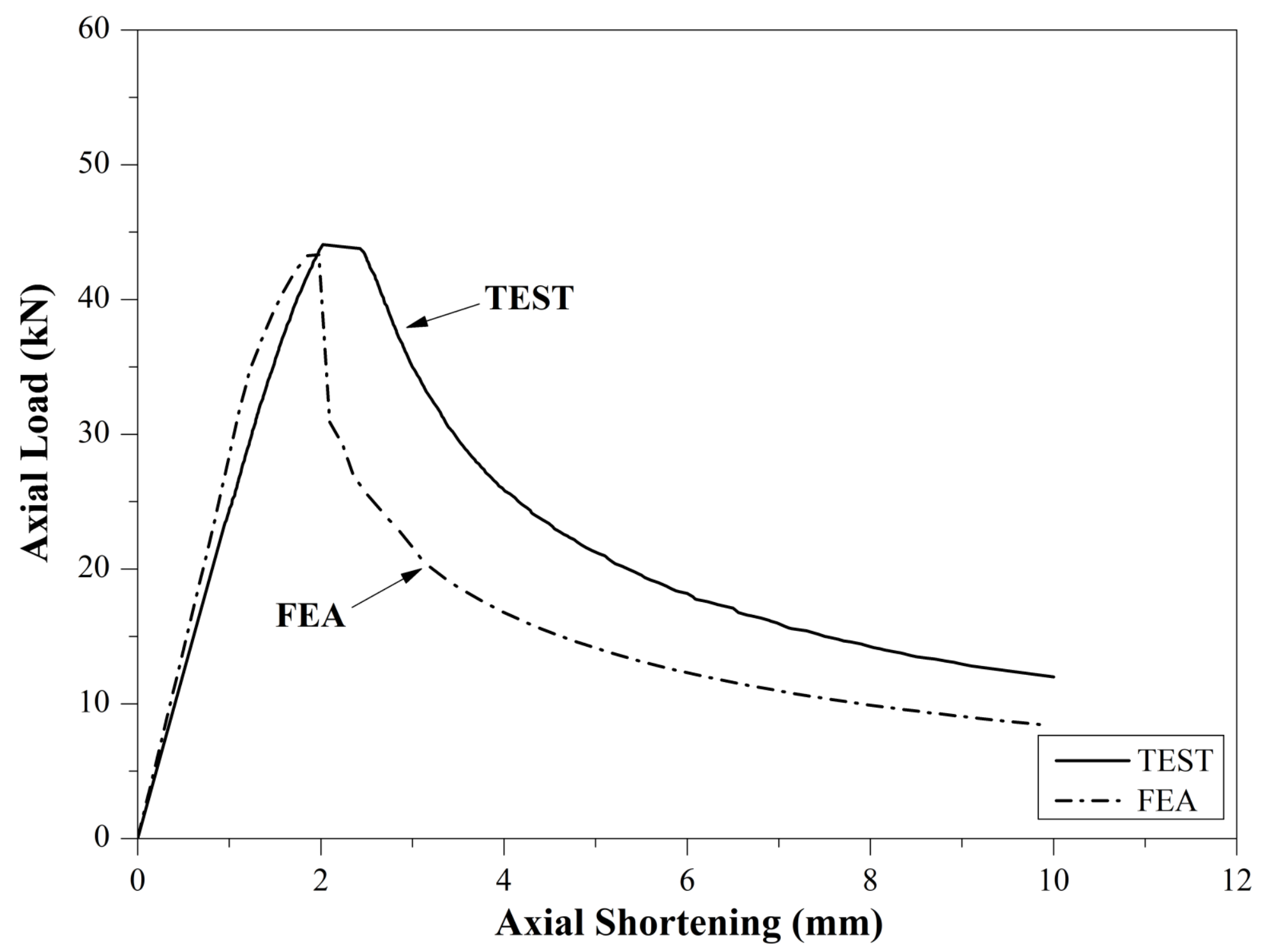

(c) $\mathrm{C} 190 \times 45 \times 15-\mathrm{L} 1500-\mathrm{UH} 7$

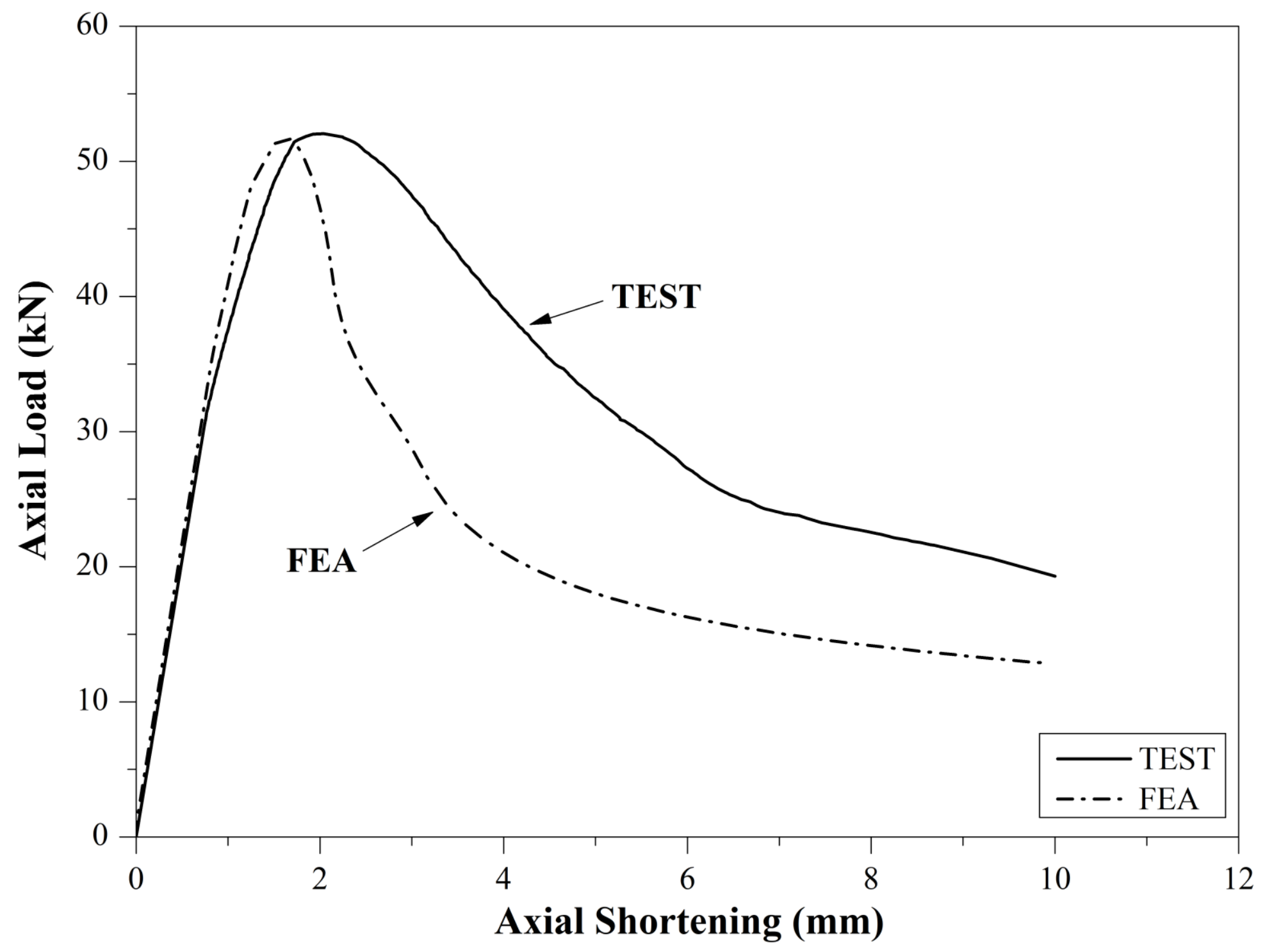

(d) C240×45×15-L1500-UH1

Fig. 22 Load versus axial displacement curves from experiments and FEA 


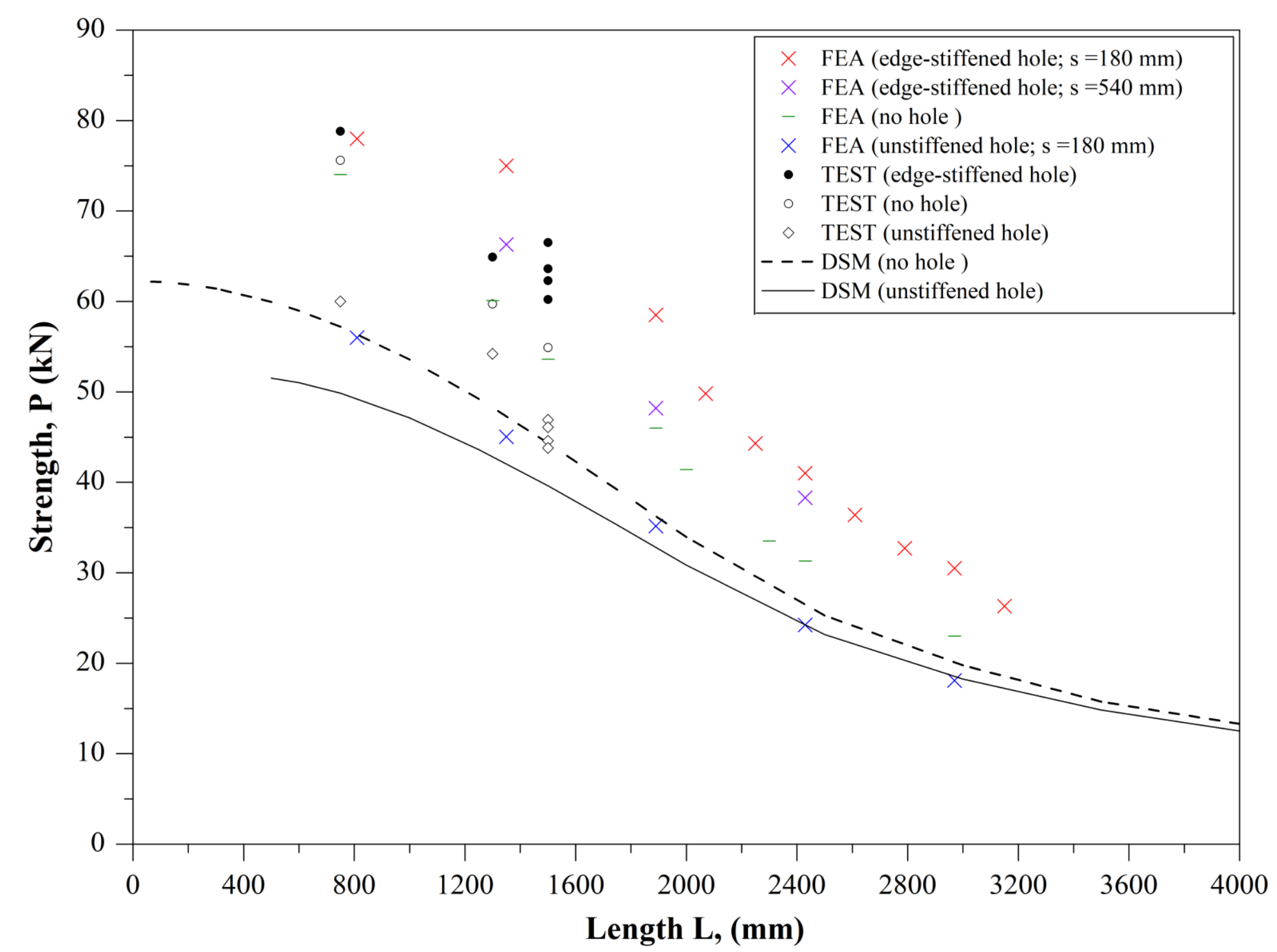

Fig. 23 Variation of strength against length for section $190 \times 45 \times 15$ 


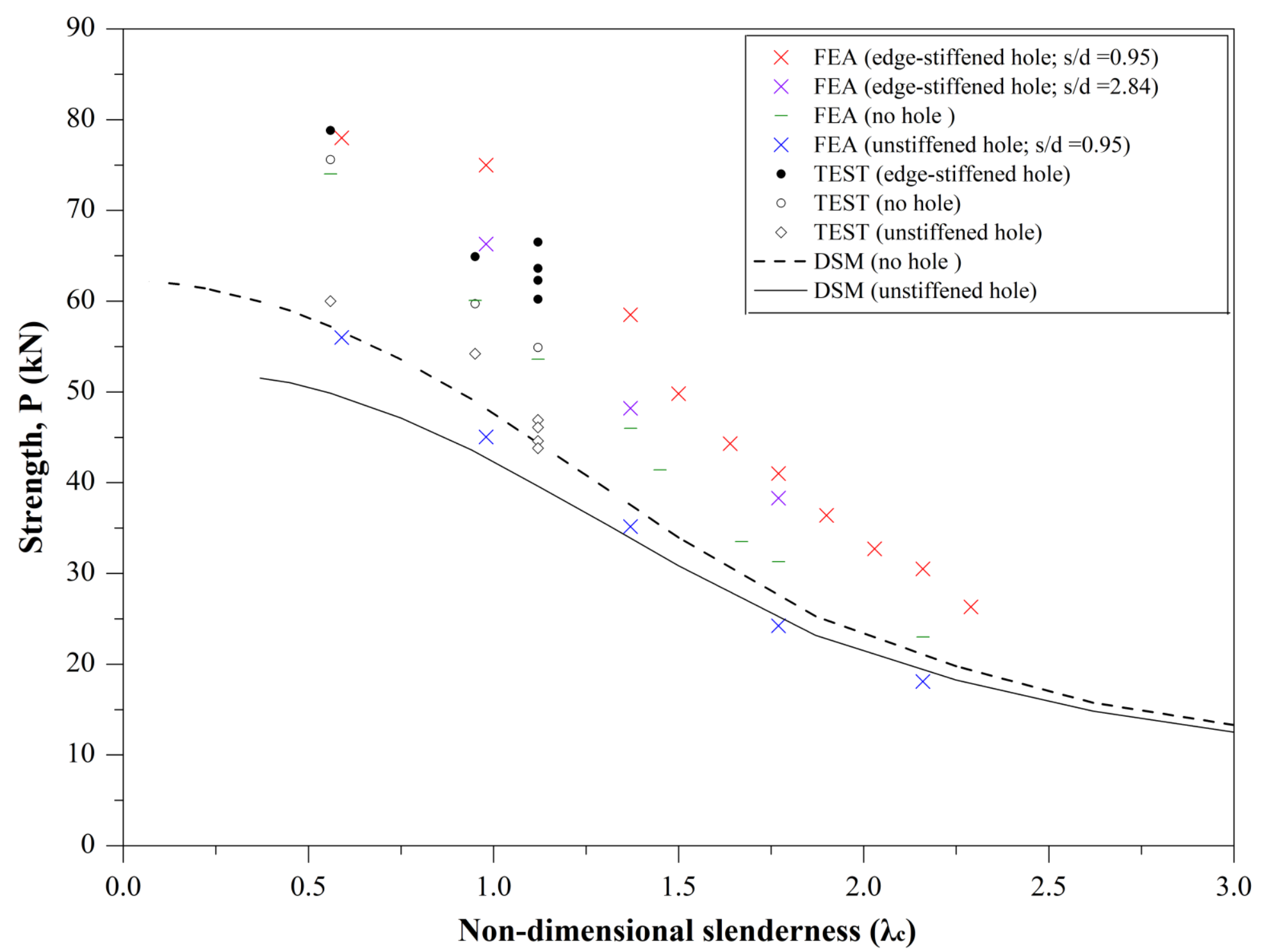

Fig. 24 Variation of strength against slenderness for section $190 \times 45 \times 15$ 